Article

\title{
Source Apportionment and Ecological Risk Assessment of Potentially Toxic Elements in Cultivated Soils of Xiangzhou, China: A Combined Approach of Geographic Information System and Random Forest
}

\author{
He Huang, Yong Zhou *, Yu-Jie Liu, Liang Xiao, Ke Li, Meng-Yao Li, Yang Tian and Fei Wu
}

check for updates

Citation: Huang, H.; Zhou, Y.; Liu, Y.-J.; Xiao, L.; Li, K.; Li, M.-Y.; Tian, Y.; Wu, F. Source Apportionment and Ecological Risk Assessment of Potentially Toxic Elements in Cultivated Soils of Xiangzhou, China: A Combined Approach of Geographic Information System and Random

Forest. Sustainability 2021, 13, 1214.

https://doi.org/10.3390/su13031214

Academic Editor: Adriano Sofo

Received: 10 January 2021

Accepted: 25 January 2021

Published: 25 January 2021

Publisher's Note: MDPI stays neutral with regard to jurisdictional claims in published maps and institutional affiliations.

Copyright: (c) 2021 by the authors. Licensee MDPI, Basel, Switzerland. This article is an open access article distributed under the terms and conditions of the Creative Commons Attribution (CC BY) license (https:// creativecommons.org/licenses/by/ $4.0 /)$.
Faculty of Urban and Environmental Sciences, Central China Normal University, Wuhan 430079, China; hhuang@mails.ccnu.edu.cn (H.H.); liuyj@mails.ccnu.edu.cn (Y.-J.L.); xiaoliang@mails.ccnu.edu.cn (L.X.); kli@mails.ccnu.edu.cn (K.L.); limengyao@mails.ccnu.edu.cn (M.-Y.L.); tianyang@mails.ccnu.edu.cn (Y.T.); wfei9527@mails.ccnu.edu.cn (F.W.)

* Correspondence: yzhou@mail.ccnu.edu.cn; Tel.: +86-1380-716-1786

\begin{abstract}
Soil is both an important sink and a source for contaminants in the agricultural ecosystem. To research the sources and ecological risk of potentially toxic elements in Xiangzhou, China, 326 soil samples from arable land were collected and analyzed for five potentially toxic elements: cadmium $(\mathrm{Cd})$, mercury $(\mathrm{Hg})$, arsenic $(\mathrm{As})$, lead $(\mathrm{Pb})$, and chromium $(\mathrm{Cr})$. In this research, ecological risk assessment was used to determine the degree of contamination in the research area, the outcome of the Geographic Information System was as used to study the spatial distribution characteristics of potentially toxic elements, and random forest was used to evaluate the natural and artificial influencing factors. We surveyed the sources of potentially toxic elements through quantifying the indicators, which gave further opinions. The results were as follows: (1) The average contents of potentially toxic elements were $0.14 \mathrm{mg} / \mathrm{kg}(\mathrm{Cd}), 0.05 \mathrm{mg} / \mathrm{kg}(\mathrm{Hg}), 12.33 \mathrm{mg} / \mathrm{kg}$ (As), $28.39 \mathrm{mg} / \mathrm{kg}$ $(\mathrm{Pb})$, and $75.21 \mathrm{mg} / \mathrm{kg}(\mathrm{Cr})$, respectively. The results compared with the background value of Hubei, neighboring regions, and countries for $\mathrm{Cd}, \mathrm{As}, \mathrm{Pb}$, and $\mathrm{Cr}$ showed mild pollution. (2) The total evaluation of soil pollution via the comprehensive pollution index indicated slight contamination by $\mathrm{Cd}$. Assessment by the potential ecological risk index indicated low ecological risk due to $\mathrm{Cd}$ and moderate contamination by $\mathrm{Hg}$. Evaluation through the geo-accumulation index evinced the low ecological risk for $\mathrm{Cd}, \mathrm{As}$, and $\mathrm{Pb}$ and moderate contamination by $\mathrm{Hg}$. (3) We found that in addition to natural factors (such as soil parent material, soil $\mathrm{pH}$, etc.), long-term industrial pollution, mineral mining and processing, exhaust emissions from transportation, the application of manure from farms as farmyard manure, and sewage irrigation were the primary anthropogenic sources of potentially toxic element contamination in the soil.
\end{abstract}

Keywords: cultivated soils; potentially toxic elements; ecological risk assessment; source analysis; random forest

\section{Introduction}

Soil is the foundation of the agricultural ecosystem for it acts as a main reservoir of organic nutrients, inorganic nutrients, and potentially toxic elements $(\mathrm{Cd}, \mathrm{Hg}, \mathrm{As}, \mathrm{Pb}$, and $\mathrm{Cr}$ are the five potentially toxic elements commonly found in cultivated land). Due to their formidable toxicity, they are collectively consulted to as the "five poisons" or potentially toxic pollutants [1]. The most common symptoms for human health of the toxicity of each toxic element were analyzed, considering their concentrations. Ecological risk assessment is a significant section of environmental impact assessment [2]. Risk assessment integrates data from ecological risk assessment models, toxicology, and soil pollution research to assess the risks and harms that pollutants pose to the environment [3]. 
With the development of environmental surveys of production areas, the spatial distribution of potentially toxic pollutants in China's basic farmland are essentially well characterized, and the source of potentially toxic element pollution has become one of the key issues that must be solved to prevent and control this pollution [4]. The sources of potentially toxic elements are complex and diverse, with contributions from parent material and contributions from anthropogenic sources are becoming more prominent, such as enterprises and factories that cause pollution to the environment, agricultural inputs, and non-point sources of atmospheric dust [5]. The complexity of sources and uncertainty in spatial variation complicate the study of the origins of potentially toxic elements [6].

Current research on developing the technology for potentially toxic elements' source analysis is mainly focused on analysis of the sink variability and expert judgment of source characteristics to establish source-sink relationships [7]. The methods used mainly include principal component analysis and positive definite principal component analysis, geostatistics, and mixed distribution models [8]. These methods have gradually clarified the reasons for the increase in potentially toxic element contents and their spatial variability [9].

However, the analysis of the reasons for the increase in the potentially toxic elements content in soil and the spatial variability has largely been based on the mastery of existing knowledge and expert judgments, and a true relationship between source and sink has not yet been established. In some cases, the uncertainty in expert judgment is large. Therefore, the further development of pollution source analysis technology requires combining the multiple tools, and their respective strengths, for the analysis of potentially toxic elements' pollution sources in the production area [10].

Geographic information system, principal component analysis, random forest, and multivariate statistical analysis can be used to assess the dimensional allocation of potentially toxic elements and identify their source [11]. To make better use of these models, researchers are increasingly using them in combination.

In this research, from the view of the relationship between the content of potentially toxic elements in cultivated fields and the comprehensive source surrounding variables, we applied principal component analysis, geographic information system analysis, and random forest analysis, in conjunction with big data, to (1) compute indices evaluating the grade of pollution and environmental hazard of potentially toxic elements referencing three indexes (the comprehensive pollution index, potential ecological risk, and geoaccumulation index) and (2) explore and quantify the driving force of natural and artificial conditions on the content and spatial distribution of potentially toxic elements in cultivated soils; and the relative contributions of each source are expected to provide effective support for the control and environmental management of potentially toxic element pollution in the region.

\section{Materials and Methods}

\subsection{Study Location}

Xiangzhou belongs to Hubei Province, China. The research region has a subtropical humid monsoon continental climate with an annual average temperature of $15.3-5.8{ }^{\circ} \mathrm{C}$ and annual average precipitation of $800-900 \mathrm{~mm}$ [12]. The agricultural land is 202,807.25 hectares, accounting for $82.22 \%$ of the total land area. The main soil type is yellow-brown soil with $1.05-3.39 \%$ soil organic matter; these kinds of soils are rich in organic matter since they are usually found in the tropical areas [13]. The yellowish-brown iron oxide goethite forms comparatively stable complexes, the enrichment of goethite would then cause a yellowing of the top soil [14]. Moreover, the soil $\mathrm{pH}$ was recorded as 4.8-7.1, and 1.5-1.6 $\mathrm{g} / \mathrm{cm}^{3}$ was the soil bulk density [15].

The four main industries in Xiangzhou include agricultural product processing, textile and clothing, equipment manufacturing, and automobile parts. This district has abundant agricultural resources, and modern agriculture that has distinctive characteristics with a strong comprehensive agricultural production capacity. The main food crops are rice, 
wheat, and corn. Xiangzhou has a convenient and open location for transportation, the whole district has superior railway, highway, and aviation facilities as well as huge potential water transport conditions. The population density in Xiangzhou is 406 persons $/ \mathrm{km}^{2}$, thus it is a densely populated area.

\subsection{Sample Analysis}

Sampling points (at a depth of 0-20 cm) were arranged in the light of the distribution of arable land in Xiangzhou, $50 \mathrm{~m}$ apart from each other, covering the entire cultivated area via a designed grid system. From a total of 326 sample points, 255 samples were collected in August 2020, and 71 samples were taken around suspected pollution sources (livestock farm, mining areas, etc.) in September 2020. Of these, 79 sample points were in paddy fields, and 247 sample points were on irrigated land and dry land. The samples were evenly distributed in the cultivated land, and each sampling point represented an area of about $8-10 \mathrm{~km}^{2}$. The points were carefully designed-after considering the difficulty of sampling, the pollution sources around the sampling points, and whether they were evenly distributed, the points were arranged on drawings.

Surface soil samples were collected from cultivated land in August 2020. First, debris was removed from the soil sample sampling site and placed into a clean cloth bag. After air-drying at room temperature and further removing plant roots, rocks, insects, and other debris, a rubber hammer was used to break the pieces and pass them through a 20-mesh $(0.90 \mathrm{~mm})$ nylon sieve. The samples were evenly mixed and divided into quarters and then sent to the laboratory for analysis and testing. The soil's physical and chemical properties-such as contents of potentially toxic elements, organic matter content, bulk density, available potassium, available phosphorus, and $\mathrm{pH}$ - were analyzed and tested in the laboratory, in strict accordance with the Ecological Geochemical Evaluation Sample Analysis Method and Technology Requirements DD 2005-03 and Regional Geochemical Sample Analysis DZ/T 0279-2016, which required control accuracy [16].

The $\mathrm{pH}$ of the soil was gauged with a $0.01 \mathrm{~mol} / \mathrm{L}$ calcium chloride $\left(\mathrm{CaCl}_{2}\right)$ solution (soil-to-liquid ratio of 1:5 mixed) for $30 \mathrm{~min}$, then kept still for $1 \mathrm{~h}$ and measured with a $\mathrm{pH}$ meter [17]. The pretreated sample $(1 \mathrm{~g})$ was exactly weighed into a polytetrafluoroethylene receptacle, to which $20 \mathrm{~mL}$ of $0.005 \mathrm{~mol} / \mathrm{L}$ diethylene triaminepentaacetic acid (DTPA), $0.01 \mathrm{~mol} / \mathrm{L}$ calcium chloride $\left(\mathrm{CaCl}_{2}\right)$, and $0.1 \mathrm{~mol} / \mathrm{L}$ triethylamine (TEA) were subjoined, and then sealed with microwave chemistry equipment created in the United States. The reaction equipment, namely a MARS5 microwave digester (Guangzhou, China), was used to implement digestion and dissolution. The microwave digestion parameters were power $1600 \mathrm{~W}, 120^{\circ} \mathrm{C}$ for $2 \mathrm{~min} ; 150^{\circ} \mathrm{C}$ for $10 \mathrm{~min}$; and $180^{\circ} \mathrm{C}$ for $20 \mathrm{~min}$. Following the completion of digestion, samples were handled at $150{ }^{\circ} \mathrm{C}$ to drive away the residual acid until only a small amount remained, and the sample was conveyed to a $10 \mathrm{~mL}$ measuring flask, in which the digestion canister was washed with a $1 \%$ (volume fraction) nitric acid solution, the measuring flask was integrated, diluted to the mark, and mixed well for use [18].

For determination of soil $\mathrm{pH}$, the selective ion electrode means was adopted. To survey and evaluate the total content of $\mathrm{Pb}$ and $\mathrm{Cr}$, plasma spectrometry was adopted-this method has many advantages, such as high detection efficiency and accuracy and simple and easy usage procedure [19]. The flameless atomic absorption method was adopted for total Cd content determination. The benefit of graphite furnace atomic absorption spectrometry is that the graphite furnace can improve the extent of element atomization [20]. For determination of the total content of As and $\mathrm{Hg}$, atomic fluorescence spectrometry was used. The certified reference sample for the quality command (GSS-8) was used to guarantee the result's accurateness. Analytical exactness for sample replicates was $\pm 10 \%$ with measurement uncertainties between the determined values and the certified values of $<5 \%$ [21]. 


\subsection{Environmental Variables}

\subsubsection{Natural Factors}

Landsat 8 data in August 2020 was used in this study. Prior to image analysis, we performed remote sensing image preprocessing in ENVI software. The soil color index (SCI) reflects the content of humus in the soil, Figure 1a, humus can absorb potentially toxic elements in the soil [22], preventing possible harm caused by their continuous diffusion in the soil and thereby reducing pollution [23]. Iron oxide is an important component of soil, yellow soil contains more hydrated iron oxide. Red soil forms iron bauxite under the action of desiliconization and aluminum enrichment [24], Figure 1b. Clay minerals reflect the distribution and content of clay in the study area, Figure 1c; its adsorption has an important influence on the content of trace elements in the soil [25]. Carboxyl, hydroxyl, carbonyl, phenolic hydroxyl, methoxy, aldehyde, ether, amine, etc. are the most important functional groups of organic matter. It is these large number of functional groups that produce high reactivity, so they can interact with metals in the environment, Figure 1d. Frequent interactions of ions influence the content of potentially toxic elements in the soil [26]. Soil bulk density is an important indicator reflecting soil porosity and permeability, Figure 1e. Potential toxic elements will dissolve, precipitate, complex, and adsorb in the soil [27]. The $\mathrm{pH}$ value of the soil affects the effectiveness of potentially toxic elements, Figure 1f. Studies have found that when the $\mathrm{pH}$ value in the soil is higher, the reactivity of potentially toxic elements will be significantly reduced, making it difficult for them to be absorbed by plants [28].
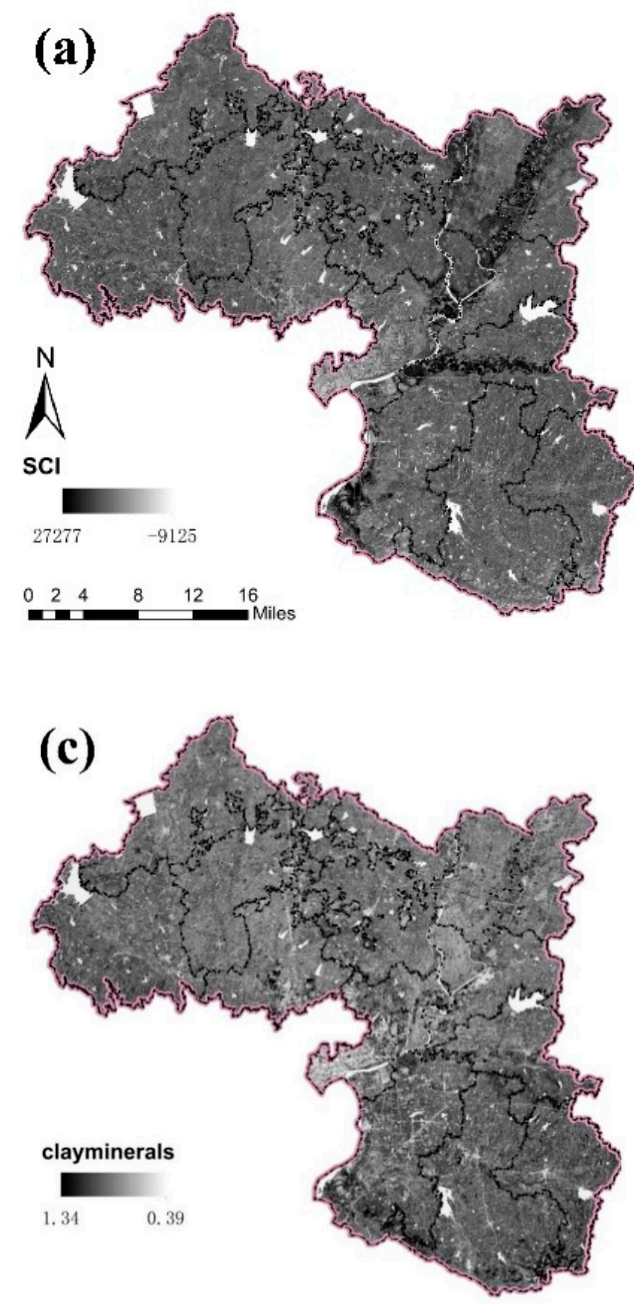
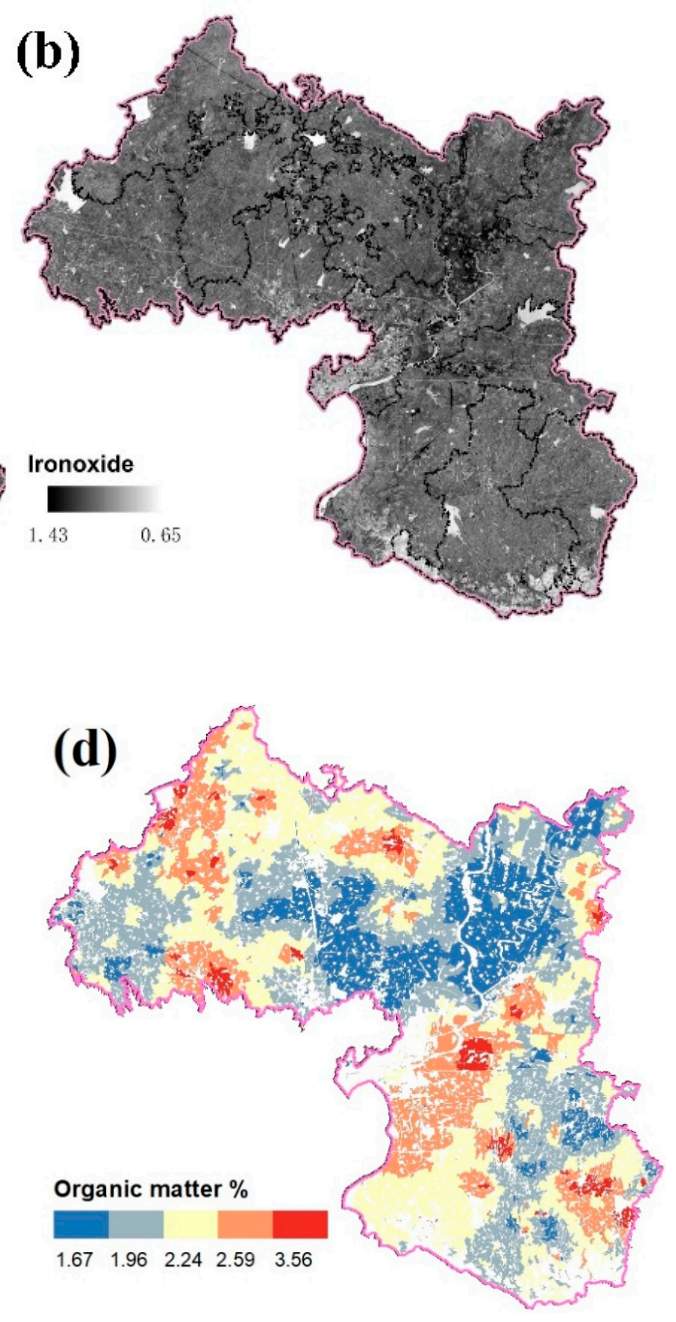

Figure 1. Cont. 

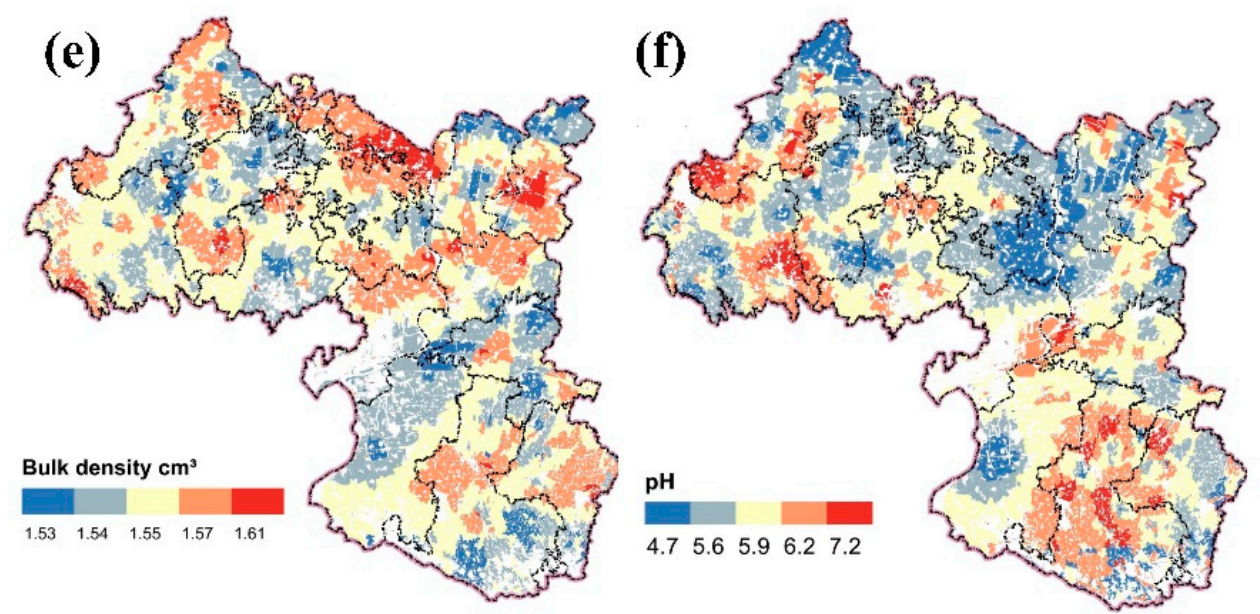

Figure 1. Natural accumulation in the study area. The spatial distribution of (a) soil color index (SCI), (b) iron oxide, (c) clay minerals, (d) organic matter, (e) bulk density, and (f) $\mathrm{pH}$.

\subsubsection{Artificial Factors}

The available phosphorus and potassium can reflect the cumulative impact of artificial fertilization on the levels of potentially toxic elements in soil, Figure $2 \mathrm{a}, \mathrm{b}$. The water system, roads, industrial enterprises, livestock farms, and mining areas were analyzed in ArcGIS software using the Euclidean distance to obtain the sample point, close to the water system and construction land, Figure 2c-g. The distances between them can illustrate the influence of human conducts on the soil environment, such as transportation, irrigation, and artificial breeding [29].

\subsection{Methodology}

\subsubsection{Analytical Framework}

A research framework with the association of multivariate statistical analysis, ecological risk assessment, correlation analysis, principal component analysis, and random forest model was built using five main steps: statistical summary, correlation analysis, principal component identification, source dedication calculation, and effect procedure analysis of important factors. Through statistical summary, the concentrations of each potentially toxic element in the study area would be revealed. Through ecological risk assessment calculation, the risk assessment integrates data from ecological risk assessment models, toxicology, and soil pollution research to assess the risks and harms that pollutants pose to environment [30]. Through correlation analysis and principal component analysis, in IBM SPSS Statistics 19 software, the main pollution sources could be determined for the study area. Then through random forest simulation, detailed sources' contribution ratio could be acquired, and the key environmental variables would be selected to indicate the effect procedure of artificial and natural indicators on potentially toxic elements in soil.

Therefore, the effect contribution, effect factors, and effect procedure of artificial activities on potentially toxic elements contents in the soil of the study area could be indicated via the combined framework of the correlation analysis and principal component analysis and the random forest model. The models require lots of data for superior simulation manifestation. Numerous number and variety of data of this research could sustain the achievement of excellent model simulation representation. The primary procedures applied in this research are illustrated in Figure 3. 

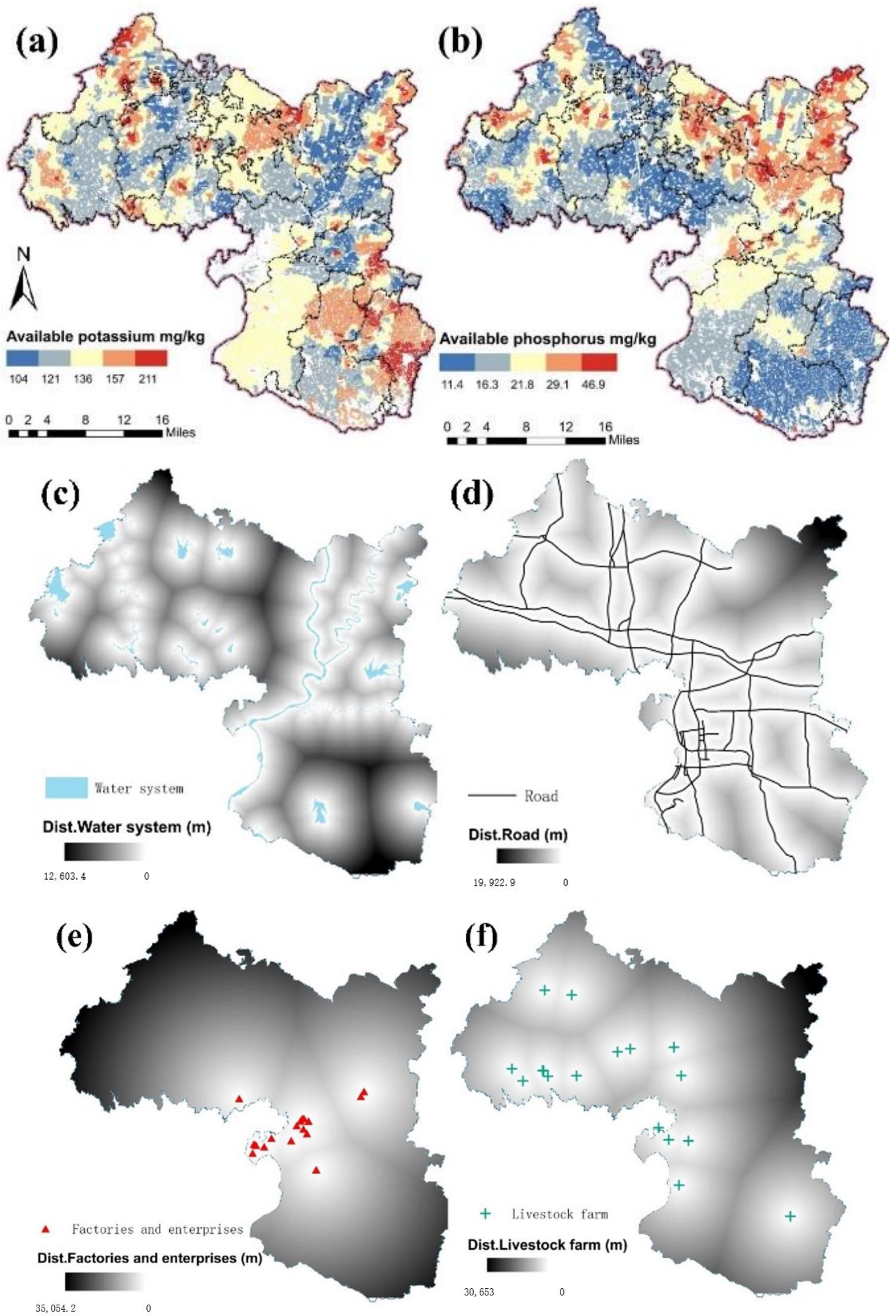

Figure 2. Cont. 


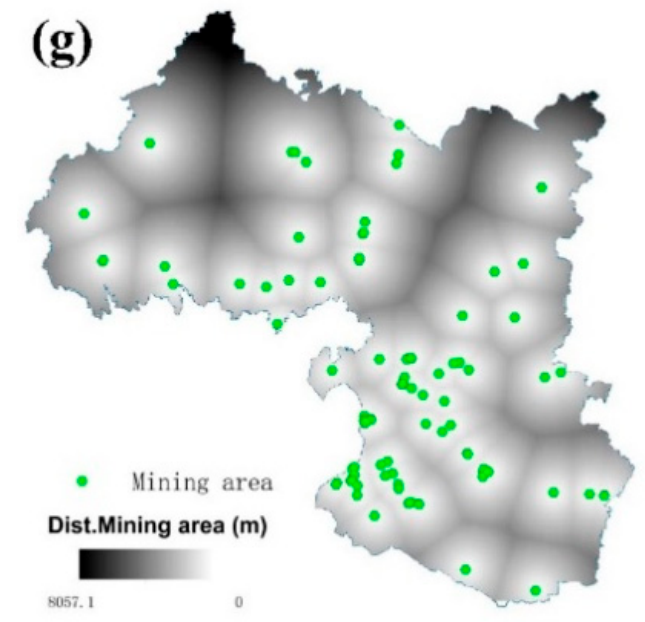

Figure 2. Human activities in the study area. The spatial distribution of (a) available potassium, (b) available phosphorus, (c) water systems, (d) roads, (e)f and enterprises, (f) livestock farms, and (g) mining areas.

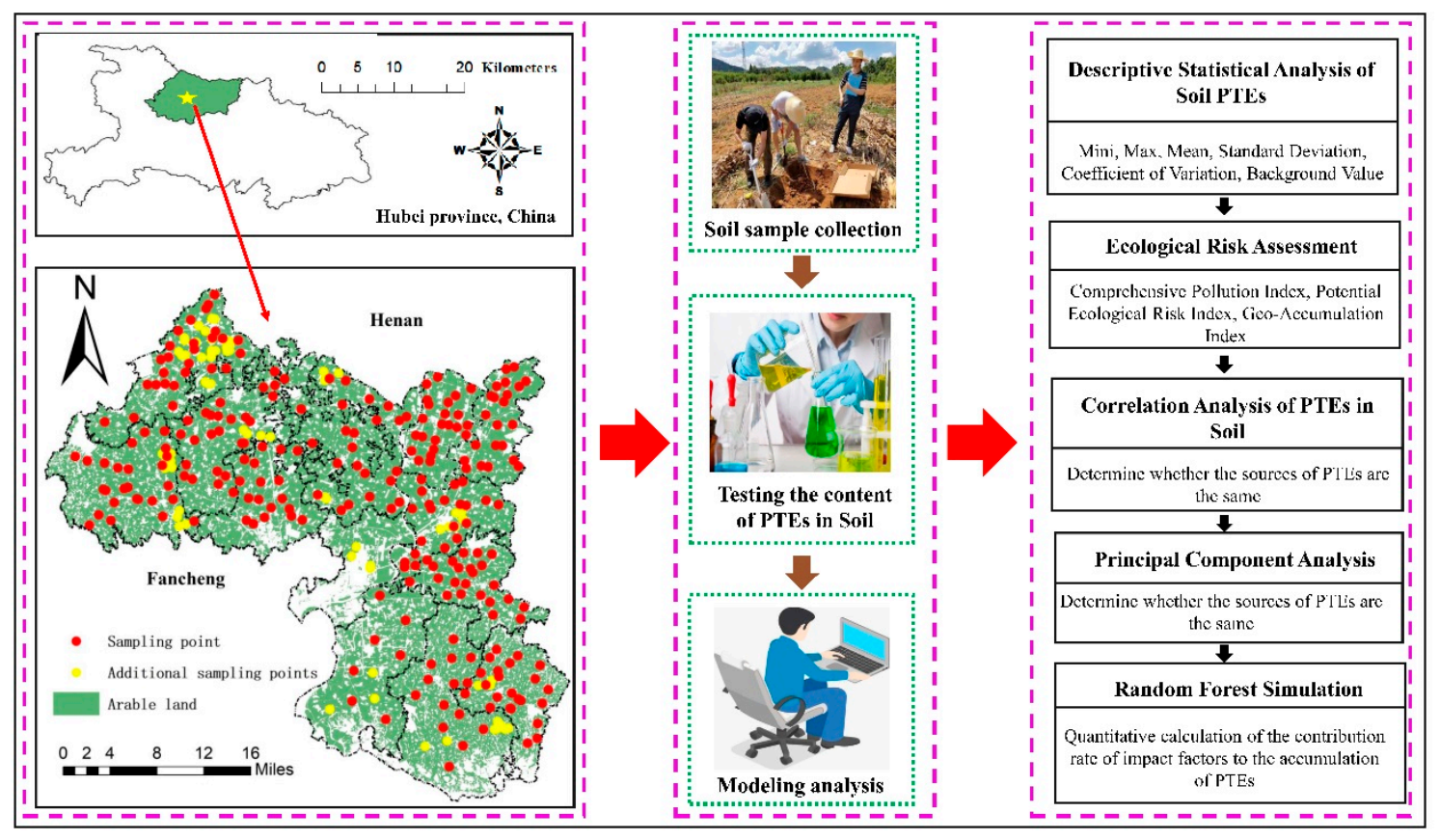

Figure 3. Schematic diagram of research ideas.

\subsubsection{Ecological Risk Assessment}

(1) Comprehensive Pollution Index

The revised formulae for calculating the comprehensive pollution index are given in Equations (1) and (2) [31]:

$$
\begin{gathered}
P_{i}=C_{i} / S_{i} \\
P=\sqrt{\left(P_{\text {imax }}^{2}+P_{\text {iave }}^{2}\right) / 2}
\end{gathered}
$$

where $P_{i}$ is the single potentially toxic element pollution index, $C_{i}$ is the actual potentially toxic element content of the sample $(\mathrm{mg} / \mathrm{kg}), S_{i}$ is the soil pollution risk screening value of agricultural land $(\mathrm{mg} / \mathrm{kg}), P_{\text {imax }}$ is the max of potentially toxic element pollution index, and $P_{\text {iave }}$ is the average of potentially toxic element pollution index, as shown in Table 1. 
Table 1. The soil pollution risk screening value of agricultural land (mg/kg).

\begin{tabular}{|c|c|c|c|c|c|}
\hline & \multirow{2}{*}{ Element } & \multicolumn{4}{|c|}{ Risk Screening Value } \\
\hline & & $\mathrm{pH} \leq 5.5$ & $5.5<\mathrm{pH} \leq 6.5$ & $6.5<\mathrm{pH} \leq 7.5$ & $\mathrm{pH}>7.5$ \\
\hline \multirow{2}{*}{$\mathrm{Cd}$} & Paddy field & 0.3 & 0.4 & 0.6 & 0.8 \\
\hline & Irrigated land, dry land & 0.3 & 0.3 & 0.3 & 0.6 \\
\hline \multirow{2}{*}{$\mathrm{Hg}$} & Paddy field & 0.5 & 0.5 & 0.6 & 1.0 \\
\hline & Irrigated land, dry land & 1.3 & 1.8 & 2.4 & 3.4 \\
\hline \multirow{2}{*}{ As } & Paddy field & 30 & 30 & 25 & 20 \\
\hline & Irrigated land, dry land & 40 & 40 & 30 & 25 \\
\hline \multirow{2}{*}{$\mathrm{Pb}$} & Paddy field & 80 & 100 & 140 & 240 \\
\hline & Irrigated land, dry land & 70 & 90 & 120 & 170 \\
\hline \multirow{2}{*}{$\mathrm{Cr}$} & Paddy field & 250 & 250 & 300 & 350 \\
\hline & Irrigated land, dry land & 150 & 150 & 200 & 250 \\
\hline
\end{tabular}

The soil was divided into five levels according to values of the comprehensive pollution index, as shown in Table 2 [32]. It should be considered that the index evaluation method is a weighted multifactor environmental quality index that considers the maximum value and is easily affected by this maximum value [33].

Table 2. The grading principle of the synthesis pollution index $(P)$.

\begin{tabular}{ccc}
\hline Level & Comprehensive Pollution Index & Comprehensive Pollution Degree \\
\hline 1 & $\leq 0.7$ & Safety \\
2 & $0.7-1.0$ & Cordon \\
3 & $1.0-2.0$ & Light pollution \\
4 & $2.0-3.0$ & Moderately polluted \\
5 & $>3.0$ & Heavy pollution \\
\hline
\end{tabular}

$P_{\text {imax }}$ is the highest potentially toxic element pollution index of the sample, $P_{\text {iave }}$ is the average potentially toxic element pollution index of the sample, and $P$ is the comprehensive potentially toxic element pollution index.

(2) Potential Ecological Risk Index

We calculated the widely used ecological risk index to evaluate the ecological risk of potentially toxic elements in cultivated soils of Xiangzhou [34]. The potentially toxic elements' potential ecological risk index method considers not only the biological toxicity of potentially toxic elements but also the comprehensive combination of multiple pollutants [35]. Potential ecological risk is widely used, which adopts a toxic-response factor for a given substance and, thus, can be used to assess the synthesized contamination risk to an ecological system [36]. The calculations are as in Equations (3) and (4) [37]:

$$
\begin{gathered}
E_{i}=T_{i} F_{i}=T_{i} \frac{C_{i}}{B_{i}} \\
R I=\sum E_{i}
\end{gathered}
$$

where $E_{i}$ is a single potentially toxic element risk factor, and $T_{i}$ is a single potentially toxic element toxicity response factor. With reference to the relevant literature, the $T$ values of the five potentially toxic elements were $30,40,10,5$, and 2 , respectively. $F_{i}$ is a single potentially toxic element pollution factor, $C_{i}$ is the actual content of potentially toxic elements in the sample $(\mathrm{mg} / \mathrm{kg}), B_{i}$ is the background value of potentially toxic elements in the region $(\mathrm{mg} / \mathrm{kg})$, and $R I$ is the sum of risk factors for the potentially toxic elements. The pollution levels and their thresholds are as shown in Table 3. 
Table 3. Classifying the standards of the potential ecological risk index and pollution degree of potentially toxic elements.

\begin{tabular}{cccccc}
\hline Level & $\begin{array}{c}\text { Potential Ecological } \\
\text { Risk Index }\end{array}$ & Degree of Risk & Level & $\begin{array}{c}\text { Comprehensive } \\
\text { Potential Ecological } \\
\text { Risk Index }\end{array}$ & Degree of Risk \\
\hline 1 & $\leq 40$ & Low potential risk & 1 & $\leq 150$ & $\begin{array}{c}\text { Minor ecological hazard } \\
\text { Medium potential risk } \\
2\end{array}$ \\
$40-80$ & High potential & 2 & $150-300$ & Moderate ecological hazard \\
3 & $80-160$ & ecological risk & 3 & $300-600$ & Strong ecological hazard \\
4 & $160-320$ & High potential risk & 4 & $>600$ & Very strong ecological hazard \\
5 & $>320$ & Very high potential risk & - & - & - \\
\hline
\end{tabular}

\section{(3) Geo-Accumulation Index}

The geo-accumulation index was used for assessing the potentially toxic elements' contamination of farmland soil due to the comprehensive influence of anthropogenic pollution factors, geochemical background values, and natural diagenesis factors that cause the background values to change [38].

The earth accumulation index is calculated as in Equation (5) [39]:

$$
I_{\text {geo }}=\log _{2}\left(\frac{C_{i}}{k B_{i}}\right)
$$

where $I_{\text {geo }}$ is the geo-accumulation index, $C_{i}$ is the content of element $i$ in the sediment $(\mathrm{mg} / \mathrm{kg}), B_{i}$ is the potentially toxic element background value of element $i$ in the area $(\mathrm{mg} / \mathrm{kg})$, and $k$ considers that diagenesis may produce potentially toxic elements. The coefficient for the change in the background value is generally 1.5. No pollution $\left(I_{\text {geo }} \leq 0\right)$ indicates no pollution, $0<I_{\text {geo }} \leq 1$ indicates no-to-moderate pollution, $1<I_{\text {geo }} \leq 2$ indicates moderate pollution, $2<I_{g e o} \leq 3$ indicates moderate-to-severe pollution, $3<I_{\text {geo }} \leq 4$ indicates serious pollution, and $4<I_{\text {geo }} \leq 5$ indicates extreme pollution.

\subsubsection{Random Forest Modeling}

To indicate the effect procedure of artificial and natural factors on potentially toxic elements in soil, a random forest model is a non-linear, non-parametric pattern proposed by Breiman [40]. The random forest model comprises many decision trees, and the dataset is recursively divided into increasingly homogeneous subsets regarding the response variable [41]. All prediction sets are examined at each split to decide which prediction sets and which result of the prediction sets best subdivides the dataset [42]. Each tree is trained by stochastically selecting a set of variables. The selecting technology is defined as bootstrap sampling. This technology could make the random forest model less prone to overfitting [43].

The random forest package that was used is from R Studio software (https: / www. rstudio.com). The important parameters of the random forest model are ntree, which determines lots of decision trees, and mtry, which is the number of distinct variables used at each node [44]. Random forest could quantify the scale of the source's influence on the contamination of the environment soil, this technique has high accuracy, and there is no longer a need to premeditate overfitting. It is an important tool used for solving source pollution sharing calculations and can effectively deal with missing data; therefore, it is extremely suitable for researching the sources of potentially toxic elements in soil [45].

The random forest package in the statistical software $R$ program (version 3.6.3) was used. The setting of mtry is often the square root of the number of variables $(p)$; in this study it was 4, and the parameter ntree was set to 1000 [46]. 


\section{Results and Discussion}

\subsection{Spatial Distribution of Potentially Toxic Elements in Soil}

To analyze the spatial distribution characteristics of the potentially toxic element soil content in the study area, the inverse distance weighting method was used in In ArcGIS software to draw the spatial distribution maps of the five potentially toxic elements, and it does not require the data to be normally distributed [47]. As shown in Figure 4, the spatial distribution of $\mathrm{Cd}$ is centered on the central old city, the $\mathrm{Cd}$ content in paddy fields near the northern waters of the study area and dry land near the hills and mountains in the south was higher than that in other areas; the $\mathrm{Hg}$ distribution is high in the surroundings and low in the middle, which presented a "basin" type distribution. The spatial distributions of $\mathrm{As}, \mathrm{Pb}$, and $\mathrm{Cr}$ are similar, all being high in the middle and lower in the surroundings.

\subsection{Descriptive Statistical Analysis of Soil Potentially Toxic Elements}

The descriptive statistical results of potentially toxic elements soil contents in the study area (Table 4), showed that the average contents of potentially toxic elements were $0.14 \mathrm{mg} / \mathrm{kg}(\mathrm{Cd}), 0.05 \mathrm{mg} / \mathrm{kg}(\mathrm{Hg}), 12.33 \mathrm{mg} / \mathrm{kg}(\mathrm{As}), 28.39 \mathrm{mg} / \mathrm{kg}(\mathrm{Pb})$, and $75.21 \mathrm{mg} / \mathrm{kg}$ $(\mathrm{Cr})$, respectively. The results compared with target values of neighboring regions and neighboring countries for $\mathrm{Cd}, \mathrm{As}, \mathrm{Pb}$, and $\mathrm{Cr}$ showed mild pollution.

The average accumulation rate (mean/background value of Hubei [48]) for As and $\mathrm{Pb}$ were 1.01 and 1.06, respectively, and the research area was confronted with contamination caused by $\mathrm{As}$ and $\mathrm{Pb}$. The ratio of the standard deviation to the average value is the coefficient of variation [49]. A descending order of the of the potentially toxic elements is: $\mathrm{Hg}(100 \%)>\mathrm{Cd}(21.43 \%)>\mathrm{As}(20.68 \%)>\mathrm{Pb}(13.88 \%)>\mathrm{Cr}(11.85 \%)$. The concentration of $\mathrm{Hg}$ ranged from 0.02 to $0.5 \mathrm{mg} / \mathrm{kg}$, varied greatly, and the coefficient of variation was beyond $100 \%$. Compared with the four other potentially toxic elements, $\mathrm{Hg}$ in the research area was extremely uneven, perhaps anthropogenic activity was the reason for the differentiation.

Table 4. The summary statistics of the soil potentially toxic elements concentrations for 326 points in Xiangzhou.

\begin{tabular}{|c|c|c|c|c|c|c|c|c|c|}
\hline \multirow[b]{2}{*}{ Element } & \multirow[b]{2}{*}{ Minimum } & \multirow[b]{2}{*}{ Maximum } & \multirow[b]{2}{*}{ Mean } & \multirow[b]{2}{*}{$\begin{array}{l}\text { Standard } \\
\text { Deviation }\end{array}$} & \multirow[b]{2}{*}{$\begin{array}{l}\text { Coefficient of } \\
\text { Variation }\end{array}$} & \multicolumn{4}{|c|}{ Background Value } \\
\hline & & & & & & $\begin{array}{l}\text { Hubei, } \\
\text { China }\end{array}$ & $\begin{array}{l}\text { Jiangsu, } \\
\text { China }\end{array}$ & $\begin{array}{c}\text { South Iran } \\
\text { [50] }\end{array}$ & $\begin{array}{c}\text { European } \\
\text { Mediterranean } \\
\text { Area [51] }\end{array}$ \\
\hline $\mathrm{Cd}(\mathrm{mg} / \mathrm{kg})$ & 0.06 & 0.28 & 0.14 & 0.03 & $21.43 \%$ & 0.17 & 0.12 & 0.17 & 0.3 \\
\hline $\mathrm{Hg}(\mathrm{mg} / \mathrm{kg})$ & 0.02 & 0.5 & 0.05 & 0.05 & $100.00 \%$ & 0.08 & - & - & - \\
\hline As $(\mathrm{mg} / \mathrm{kg})$ & 6.54 & 19.8 & 12.33 & 2.55 & $20.68 \%$ & 12.3 & 10.0 & 7.65 & - \\
\hline $\mathrm{Pb}(\mathrm{mg} / \mathrm{kg})$ & 20.1 & 47.1 & 28.39 & 3.94 & $13.88 \%$ & 26.7 & 26.2 & 10.8 & 23.0 \\
\hline $\mathrm{Cr}(\mathrm{mg} / \mathrm{kg})$ & 52.9 & 96.7 & 75.21 & 8.91 & $11.85 \%$ & 86.0 & $77.8-$ & 74.5 & 27.0 \\
\hline $\mathrm{pH}$ & 8.23 & 4.20 & 5.74 & 0.92 & $0.16 \%$ & - & & & \\
\hline $\begin{array}{l}\text { Available } \\
\text { potassium } \\
(\mathrm{mg} / \mathrm{kg})\end{array}$ & 46.90 & 4.70 & 17.08 & 8.49 & $0.50 \%$ & - & & & \\
\hline $\begin{array}{l}\text { Bulk density } \\
\left(\mathrm{cm}^{3}\right)\end{array}$ & 1.61 & 1.49 & 1.55 & 0.02 & $0.01 \%$ & - & & & \\
\hline $\begin{array}{l}\text { Organic } \\
\text { matter (\%) }\end{array}$ & 3.39 & 1.05 & 1.97 & 0.40 & $0.02 \%$ & - & & & \\
\hline $\begin{array}{l}\text { Available } \\
\text { phosphorus } \\
(\mathrm{mg} / \mathrm{kg})\end{array}$ & 46.90 & 4.70 & 17.08 & 8.49 & $0.50 \%$ & - & & & \\
\hline $\begin{array}{l}\text { Soil color } \\
\text { index (SCI) }\end{array}$ & $15,971.00$ & -1038.00 & 5377.78 & 1886.50 & $0.35 \%$ & - & & & \\
\hline Iron oxide & 1.04 & 0.89 & 0.96 & 0.02 & $0.03 \%$ & - & & & \\
\hline $\begin{array}{l}\text { Clay } \\
\text { minerals }\end{array}$ & 1.20 & 1.05 & 1.12 & 0.02 & $0.02 \%$ & - & & & \\
\hline
\end{tabular}



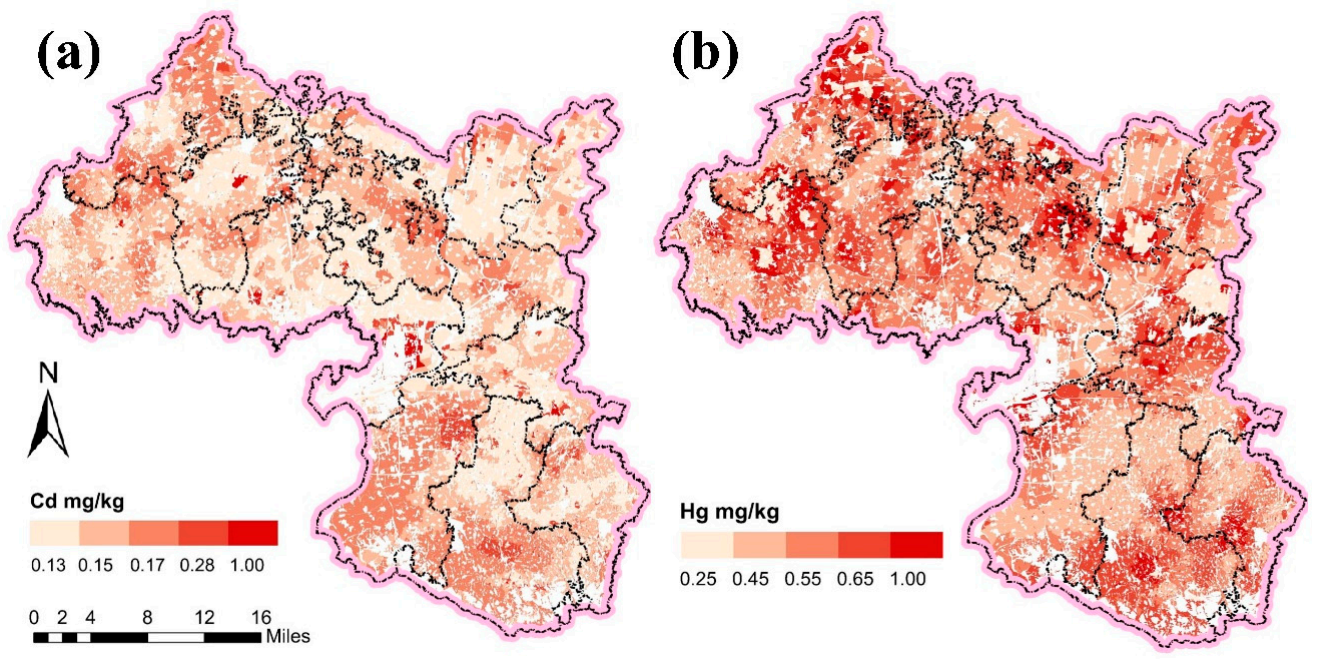

Figure 4. Cont.
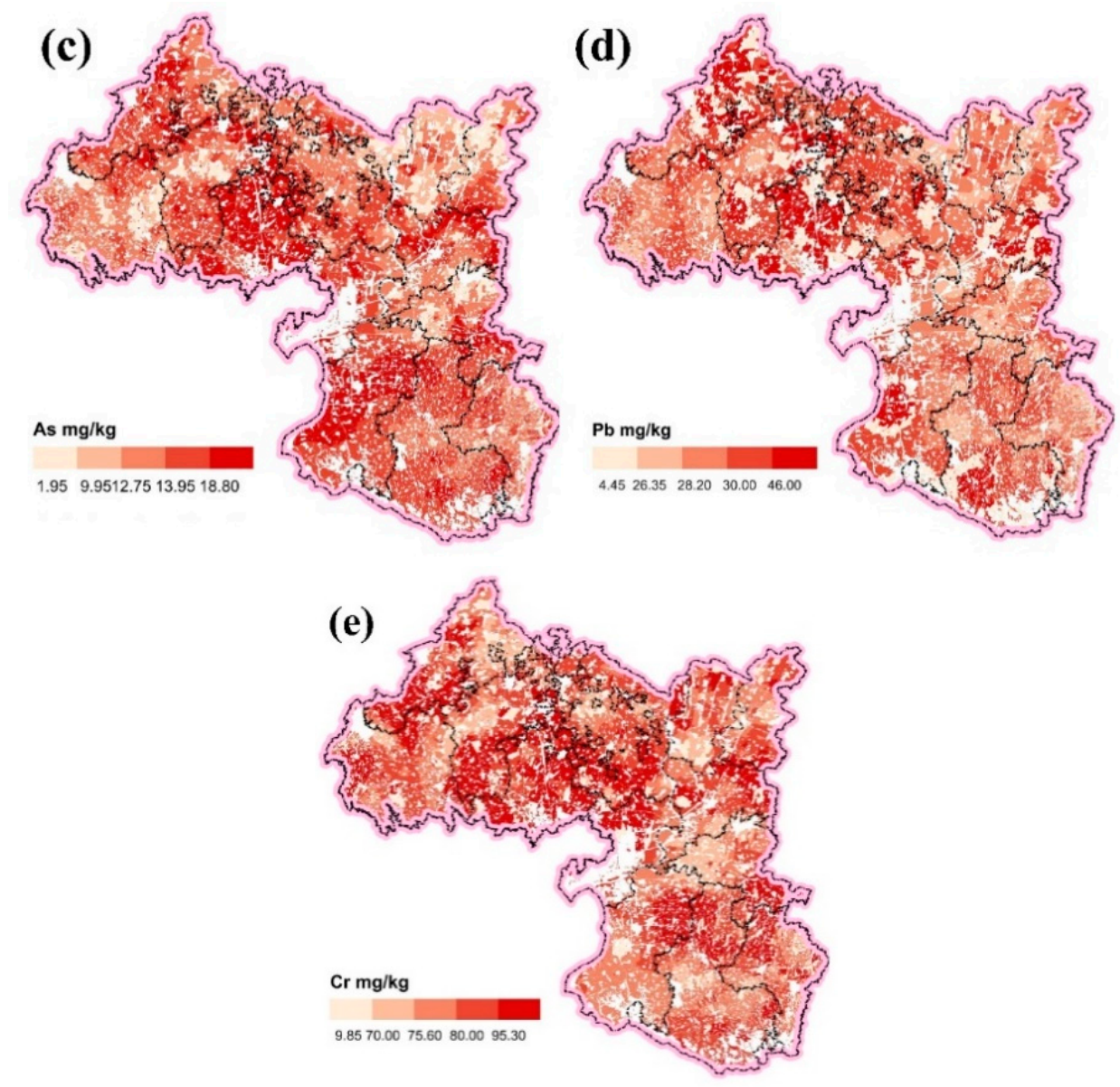

Figure 4. Spatial distribution of potentially toxic elements in soil in the study area. (a) Spatial distribution of $\mathrm{Cd}$; (b) spatial distribution of $\mathrm{Hg}$; (c) spatial distribution of As; (d) spatial distribution of $\mathrm{Pb}$; (e) spatial distribution of $\mathrm{Cr}$. 


\subsection{Ecological Risk Assessment Results}

\subsubsection{Comprehensive Pollution Index}

According to the evaluation of the comprehensive pollution index, in paddy fields, dry land, and water-irrigated fields with a $\mathrm{pH}$ less than 5.5, Cd was within the range of the warning threshold, and the other elements were within safe levels. In paddy fields (Table 5), the degree of pollution in the surface soil collected from different plots due to the different toxic elements was of the order $\mathrm{As}(0.53)>\mathrm{Cd}(0.42)>\mathrm{Cr}(0.29)>\mathrm{Hg}(0.28)>\mathrm{Pb}$ (0.26). In dry land and irrigated land (Table 6), this order was $\mathrm{Cd}(0.56)>\mathrm{As}(0.47)=\mathrm{Cr}$ (0.47) $>\mathrm{Pb}(0.35)>\mathrm{Hg}(0.16)$.

Table 5. The results for evaluation of comprehensive pollution index (paddy fields).

\begin{tabular}{cccccc}
\hline $\mathbf{p H}$ & $\mathbf{C d}$ & $\mathbf{H g}$ & $\mathbf{A s}$ & $\mathbf{P b}$ & $\mathbf{C r}$ \\
\hline$<5.5$ & 0.73 & 0.42 & 0.50 & 0.40 & 0.34 \\
$5.5-6.5$ & 0.38 & 0.11 & 0.47 & 0.30 & 0.34 \\
$6.5-7.5$ & 0.34 & 0.14 & 0.59 & 0.23 & 0.27 \\
$>7.5$ & 0.21 & 0.45 & 0.54 & 0.10 & 0.19 \\
Ave & 0.42 & 0.28 & 0.53 & 0.26 & 0.29 \\
\hline
\end{tabular}

Table 6. The results for evaluation of comprehensive pollution index (dry land and water-irrigated fields).

\begin{tabular}{cccccc}
\hline $\mathbf{p H}$ & $\mathbf{C d}$ & $\mathbf{H g}$ & $\mathbf{A s}$ & $\mathbf{P b}$ & $\mathbf{C r}$ \\
\hline$<5.5$ & 0.71 & 0.41 & 0.39 & 0.53 & 0.57 \\
$5.5-6.5$ & 0.64 & 0.07 & 0.36 & 0.35 & 0.55 \\
$6.5-7.5$ & 0.60 & 0.12 & 0.48 & 0.32 & 0.41 \\
$>7.5$ & 0.27 & 0.03 & 0.66 & 0.19 & 0.34 \\
Ave & 0.56 & 0.16 & 0.47 & 0.35 & 0.47 \\
\hline
\end{tabular}

\subsubsection{Potential Ecological Risk Index}

The outcomes for the assessment of potential ecological risk due to pollution of soil with potentially toxic elements in the study area (Table 7) showed that the average value of the potential ecological risk coefficient was of the order $\mathrm{Hg}(25.83)>\mathrm{Cd}(24.48)>\mathrm{As}$ (10.02) $>\mathrm{Pb}$ (5.32) > Cr (1.75). The ecological risk level due to $\mathrm{As}, \mathrm{Pb}$, and $\mathrm{Cr}$ was considered slight. Cd was mainly determined to pose a slight ecological risk, though in some cases, the risk was medium. The ecological risk for $\mathrm{Hg}$ was mainly slight and partly medium and strong.

Table 7. The evaluation results of the potential ecological risk index.

\begin{tabular}{cccccccc}
\hline & Statistical & Cd & Hg & As & Pb & Cr & RI \\
\hline \multirow{2}{*}{$\begin{array}{c}\text { Potential ecological risk } \\
\text { index statistics }\end{array}$} & Min & 11.29 & 8.00 & 5.32 & 3.76 & 1.23 & 38.01 \\
& Max & 49.41 & 250 & 16.10 & 8.82 & 2.25 & 292.56 \\
& Ave & 24.48 & 25.83 & 10.02 & 5.32 & 1.75 & 67.39 \\
\hline \multirow{2}{*}{ Distribution of the potential } & $\leq 40$ & $98.77 \%$ & $89.57 \%$ & $100 \%$ & $100 \%$ & $100 \%$ & $98.77 \%$ \\
ecological risk index (\%) & $(40,80]$ & $1.23 \%$ & $7.97 \%$ & - & - & - & $1.23 \%$ \\
& $(160,320]$ & - & $1.53 \%$ & - & - & - & - \\
& $>320$ & - & $0.92 \%$ & - & - & - & - \\
\hline
\end{tabular}

$R I$ is explicitly applied to infer quantitatively the ecological risk of potentially toxic elements. The average value of the potential ecological risk index was 67.39, of which the level of slight ecological risk accounted for $98.77 \%$, indicating that the potentially toxic elements in the research region soil were mainly at the slight ecological risk standard.

Among the 326 sampling points, 4 sampling points were classified as $150<R I<300$, which indicates a moderate risk of ecological hazard; 4 sampling points were classified as 
$40<E_{C d}<80$, which indicates a moderate degree of potential risk; 26 sampling points were categorized as $40<E_{\mathrm{Hg}}<80$, meaning a medium potential risk; 5 sampling points were categorized as $80<E_{\mathrm{Hg}}<160$, indicating a medium-to-high potential ecological risk; and 3 sampling points were at $160<E_{\mathrm{Hg}}<320$, indicating a high potential risk.

The contribution of various potentially toxic elements to the potential ecological risk index is equal to the ratio of its individual potential ecological risk modulus to the potential ecological risk index. The contribution rates of potentially toxic elements to the potential ecological risk index were $36.33 \%(\mathrm{Cd}), 38.33 \%(\mathrm{Hg}), 14.87 \%(\mathrm{As}), 7.89 \%(\mathrm{~Pb})$, and $2.60 \%$ $(\mathrm{Cr})$, respectively, indicating that $\mathrm{Cd}$ and $\mathrm{Hg}$ were the main risk factors.

Inverse distance weighting interpolation was performed in ArcGIS software on the potential ecological risk coefficients of the sample points, as shown in Figure 5a-e, where the potential risk index of $\mathrm{Cd}$ is shown to be relatively high in the northeast, and the spatial distribution of the potential risk index of $\mathrm{Hg}$ is scattered from the center to the surroundings. The spatial distributions of the potential risk index of $\mathrm{As}, \mathrm{Pb}$, and $\mathrm{Cr}$ were relatively similar and successively decreasing, and these elements were all higher in the northeast and middle-east. The spatial distribution of the potential ecological hazard index is shown in Figure 5f. Strong-very strong ecological risk was found to be mainly distributed in the northeastern and central and western towns.

\subsubsection{Geo-Accumulation Index Method}

The evaluation results of the $I_{g e o}$ (geo-accumulation index) of the five potentially toxic elements of the 326 sample points are shown in Table 8 . There is a certain degree of pollution in some areas. Among them, $0<I_{g e o}<1$ for $\mathrm{Cd}$, that is, there were 2 points with moderate pollution. For $\mathrm{Hg}$, 8 points had $0<I_{g e o}<1$, that is, moderate pollution; $1<I_{\text {geo }}<2$ for 3 points, which is a medium pollution degree; and $2<I_{\text {geo }}<3$ for 1 point, which is extreme pollution. For As, there was 1 point with $0<I_{g e o}<1$, which is a moderate pollution degree. For $\mathrm{Pb}, 5$ points were $0<I_{g e o}<1$, which indicates a moderate pollution degree.

Table 8. The evaluation results of the geo-accumulation index method.

\begin{tabular}{cccccc}
\hline$I_{\text {geo }}$ & $\mathbf{C d}$ & $\mathbf{H g}$ & $\mathbf{A s}$ & $\mathbf{P b}$ & $\mathbf{C r}$ \\
\hline Min & -1.99 & -2.91 & -1.50 & -0.99 & -1.29 \\
Max & 0.13 & 2.06 & 0.10 & 0.23 & -0.42 \\
Ave & -0.91 & -1.46 & -0.62 & -0.51 & -0.79 \\
\hline
\end{tabular}

Figure 3 shows the inverse distance weighting of $I_{g e o}$ in ArcGIS software. The highvalue area of $\mathrm{Cd}$ is mainly concentrated in the northwest region, Figure 6a. The spatial distribution of the geo-accumulative index of $\mathrm{Hg}$ is scattered from the center to the surroundings and then decreases in sequence, Figure $6 \mathrm{~b}$. The spatial distributions of the potential risk index for $\mathrm{As}, \mathrm{Pb}$, and $\mathrm{Cr}$ were relatively similar, being higher in the northeast, central, and eastern regions, Figure 6c-e.

\subsection{Correlation Analysis of Potentially Toxic Elements in Soil}

Spearman correlation analysis was performed on the data of the five potentially toxic elements in 326 soil samples using SPSS 22 software (Table 9 and Figure 7), and was chosen because it does not require normality of variables. The correlations between $\mathrm{As}$ and $\mathrm{Pb}$ and between As and $\mathrm{Cr}$ were found to be 0.393 and 0.466 , respectively, indicating a greater likelihood of having common sources. The correlations between $\mathrm{Hg}$ and $\mathrm{Pb}, \mathrm{Cd}$ and $\mathrm{Hg}$, and $\mathrm{Pb}$ and $\mathrm{Cr}$ were $0.273,0.215$, and 0.184 , respectively, indicating that they may have a common source. 

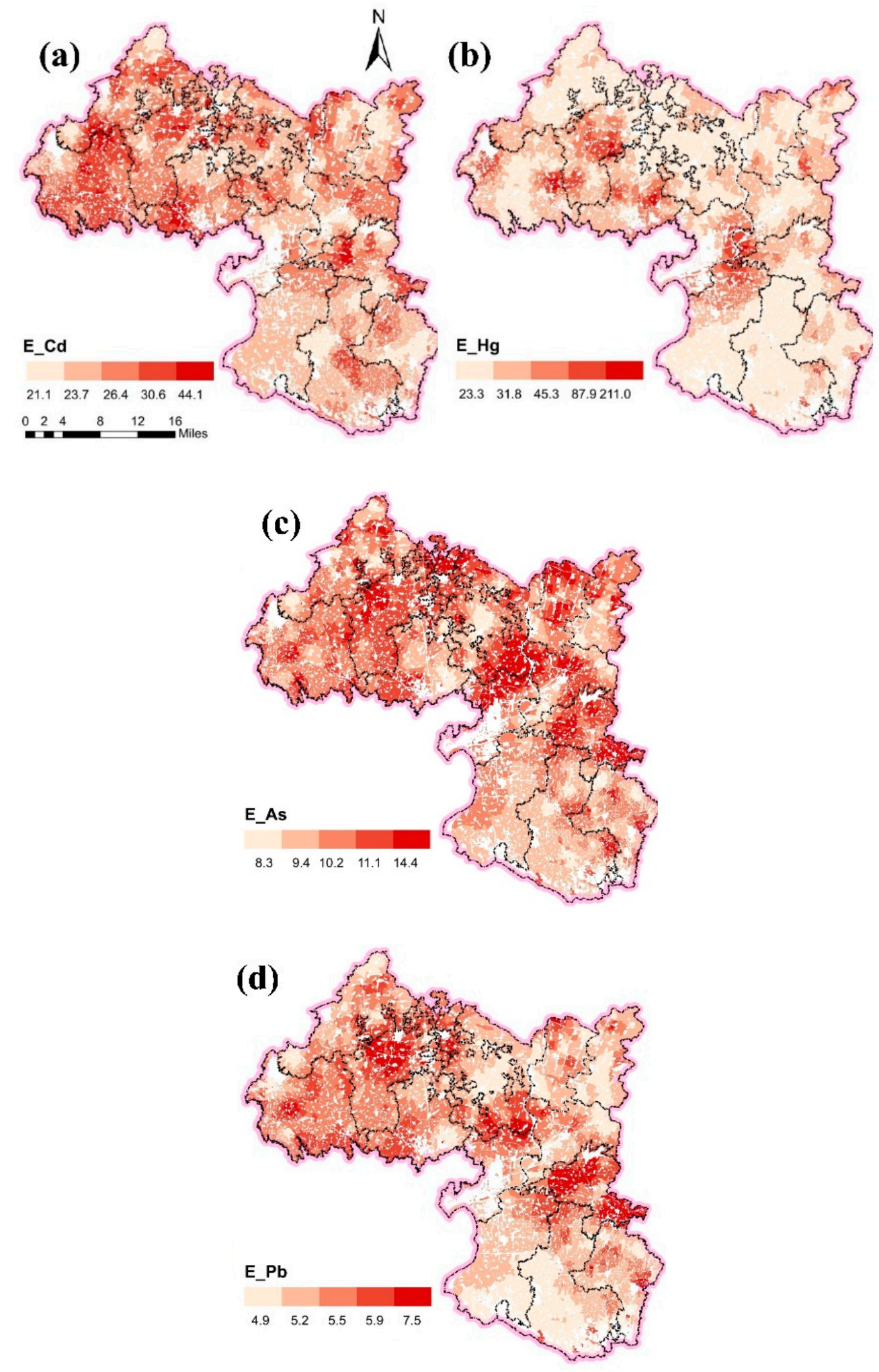

Figure 5. Cont. 

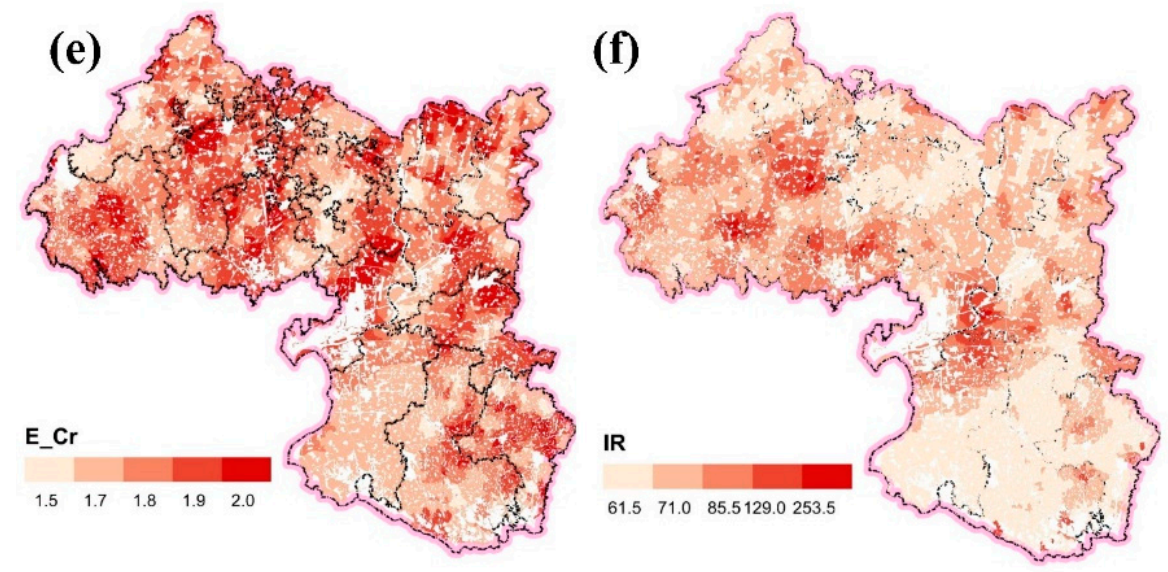

Figure 5. The spatial distribution of the potential ecological risk coefficient in the research region shown individually for (a) $\mathrm{Cd}$, (b) $\mathrm{Hg}$, (c) As, (d) $\mathrm{Pb}$, (e) $\mathrm{Cr}$ and (f) IR.
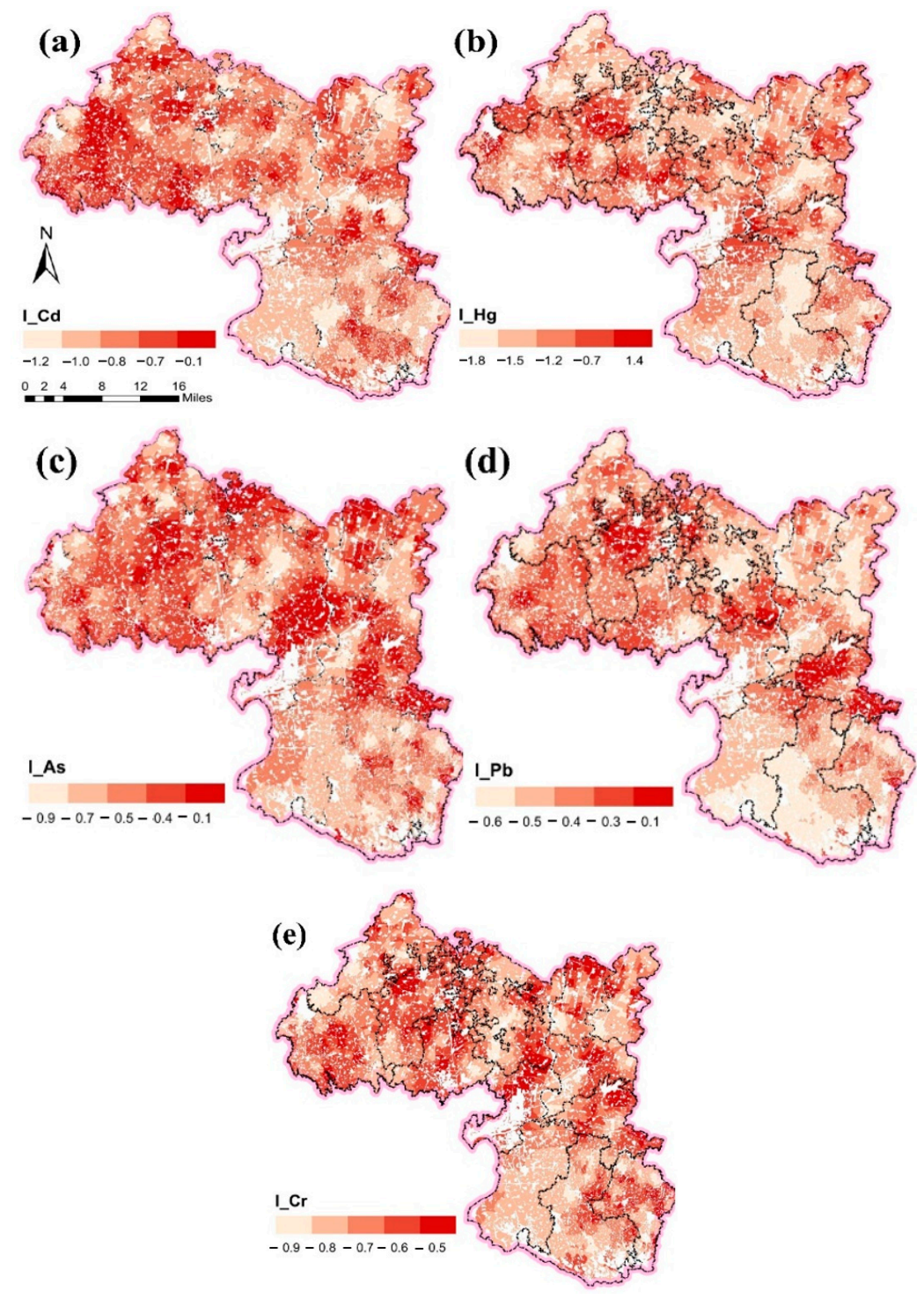

Figure 6. The spatial distribution of $I_{g e o}$ (geo-accumulation index) in the study area shown individually for (a) Cd, (b) $\mathrm{Hg}$, (c) As, (d) Pb, and (e) Cr. 
Table 9. Correlation analysis of potentially toxic elements concentrations in research area.

\begin{tabular}{cccccc}
\hline Element & $\mathbf{C d}$ & $\mathbf{H g}$ & $\mathbf{A s}$ & $\mathbf{P b}$ & $\mathbf{C r}$ \\
\hline $\mathrm{Cd}$ & 1.000 & & & & \\
$\mathrm{Hg}$ & $0.215^{* *}$ & 1.000 & & & \\
$\mathrm{As}$ & $0.107^{* *}$ & -0.044 & 1.000 & & \\
$\mathrm{~Pb}$ & $0.228^{* *}$ & $0.273^{* *}$ & $0.393^{* *}$ & 1.000 & \\
$\mathrm{Cr}$ & $0.006^{* *}$ & $-0.223^{* *}$ & $0.466^{* *}$ & $0.184^{* *}$ & 1.000 \\
\hline
\end{tabular}

** Significantly correlated at the 0.01 level (bilateral).

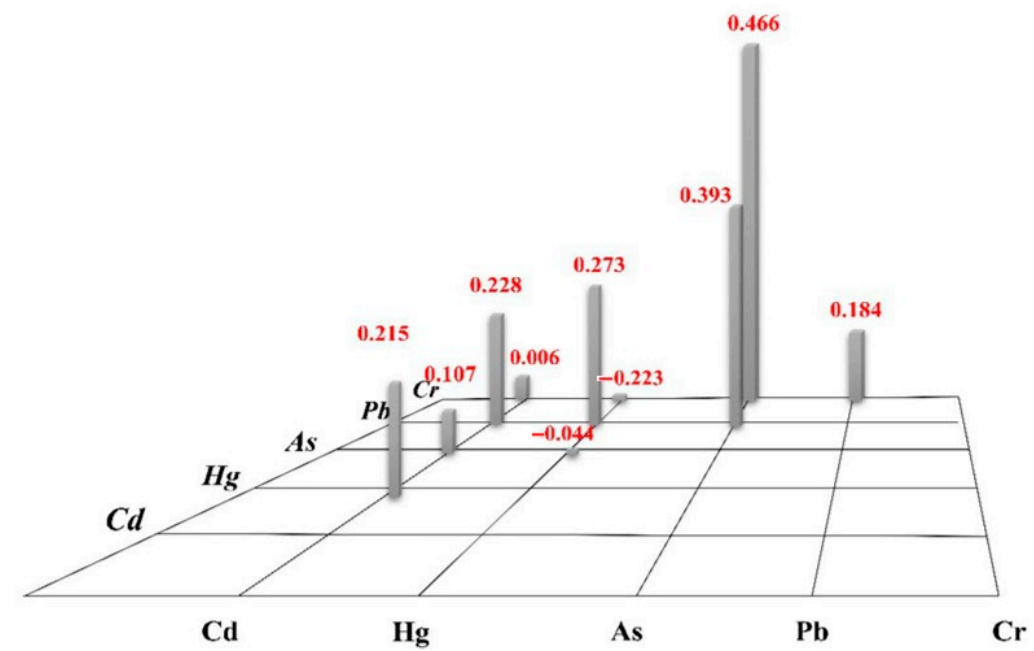

Figure 7. Correlation analysis of potentially toxic element concentrations in research area.

\subsection{Principal Component Analysis}

The Kaiser-Meyer-Olkin and Bartlett sphere test were carried out in SPSS software. The Kaiser-Meyer-Olkin was $0.528>0.5$, and $P$ was 0.0000 . That is, the related feasibility of the Bartlett sphericity test was $0.0000<0.05$; therefore, the specimen data can be subjected to principal component analysis.

The Kaiser standardized orthogonal rotation method was used for principal component analysis, as shown in Table 10 and Figure 8. The multivariate was reduced to three factors (the characteristic root was greater than one). The first three components illustrated $69.88 \%$ of the total variable variance. The main variables of the first main factor (which explained $28.01 \%$ of the total variance) included $\mathrm{Hg}$ and $\mathrm{Pb}$, indicating that these two elements have a high degree of homology; the second main factor (the increase explained $22.04 \%$ of the total variance) included Cd; the main variables of the third main factor (an increase of $19.84 \%$ ) were As and Cr.

Table 10. The results of principal component analysis.

\begin{tabular}{cccc}
\hline & \multicolumn{2}{c}{ Factor Load (Orthogonal Rotation) } \\
\cline { 2 - 4 } Metals & $\begin{array}{c}\text { Principal } \\
\text { Component 1 }\end{array}$ & $\begin{array}{c}\text { Principal } \\
\text { Component 2 }\end{array}$ & $\begin{array}{c}\text { Principal } \\
\text { Component 3 }\end{array}$ \\
\hline $\mathrm{Cd}$ & -0.16 & 0.78 & 0.29 \\
$\mathrm{Hg}$ & 0.79 & 0.13 & -0.01 \\
$\mathrm{As}$ & 0.05 & 0.06 & 0.91 \\
$\mathrm{~Pb}$ & 0.79 & -0.11 & 0.01 \\
$\mathrm{Cr}$ & -0.28 & -0.66 & 0.39 \\
\% Variance contribution rate & 28.01 & 22.04 & 19.84 \\
\% Cumulative contribution rate & 28.01 & 50.05 & 69.88 \\
\hline
\end{tabular}




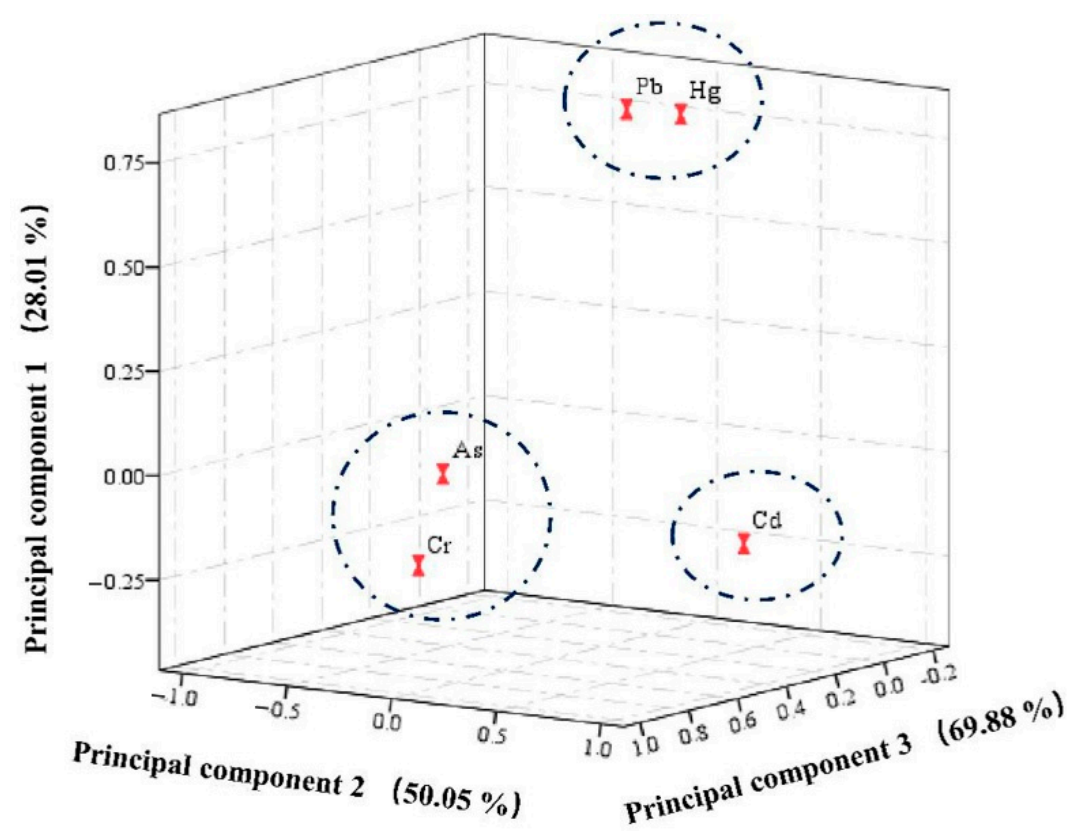

Figure 8. The results of principal component analysis.

\subsection{Random Forest Simulation}

The random forest package in the statistical software $\mathrm{R}$ program (version 3.6.3) was used. The setting of mtry is often the square root of the number of variables $(p)$; in this study it was 4, and the parameter ntree was set to 1000 [52].

In this research, the following means to using legacy data for training model was applied: the ratio of the training set (260 samples) and the validation set (66 samples) was set to $8: 2$, and the overall accuracy $r^{2}$ (correlation coefficient) of the models for potentially toxic elements was $93.35 \%, 95.88 \%, 94.11 \%, 93.95 \%$, and $93.20 \%$, respectively, indicating high accuracy. The results of the variable importance measure are listed in Table 11.

As shown in Figure 9, the variable importance measure represents the weight of the anthropogenic influencing factors. The top four factors explaining $\mathrm{Cd}$ were factories and enterprises $(6.03 \%)>$ water $(4.61 \%)>$ soil color index $(\mathrm{SCI})(3.12 \%)>$ available phosphorus $(2.89 \%)$, Figure $9 \mathrm{a}$. The top four factors explaining $\mathrm{Hg}$ were factories and enterprises $(12.41 \%)>$ mining areas $(10.77 \%)>$ available phosphorus $(7.05 \%)>$ water $(6.12 \%)$, Figure $9 \mathrm{~b}$. The top four factors explaining As were roads $(11.11 \%)>$ iron oxide $(10.21 \%)>$ factories and enterprises $(8.94 \%)>$ mining areas $(7.39 \%)$, Figure 9c. The top four factors explaining $\mathrm{Pb}$ were factories and enterprises $(12.40 \%)>$ livestock farms $(10.69 \%)>$ mining areas $(8.25 \%)>$ organic matter $(6.89 \%)$, Figure $9 \mathrm{~d}$. The top four factors explaining $\mathrm{Cr}$ were mining areas $(7.10 \%)>$ roads $(6.83 \%)>$ available potassium $(6.80 \%)>$ factories and enterprises $(6.73 \%)$, Figure 9e.

The random forest results showed that among the top four factors affecting $\mathrm{Cd}$, factories and enterprises, agricultural irrigation, artificial fertilization, and road transportation were the most important factors, which demonstrated that the accumulation of Cd was primarily from human activities [53]. Potentially toxic elements from farm animals may enter the nearby agricultural land in the form of farm manure, once again verifying the accuracy of the results [54]. The long-term application of chemical fertilizers (such as phosphate fertilizer and potash fertilizer) in agricultural activities and farmland farming methods that use sewage containing a large amount of potentially toxic elements for irrigation will significantly increase the accumulation and contents of potentially toxic elements in farmland soil [55]. 
Table 11. Results of the variable importance measure in Xiangzhou.

\begin{tabular}{cccccc}
\hline Variable Importance Measure & $\mathbf{C d}$ & $\mathbf{H g}$ & $\mathbf{A s}$ & $\mathbf{P b}$ & $\mathbf{C r}$ \\
\hline $\mathrm{pH}$ & 0.79 & 2.58 & 1.19 & 1.27 & 1.41 \\
Bulk density & 1.31 & 3.93 & 3.15 & 5.99 & 1.57 \\
Organic matter & 0.93 & 5.06 & 1.82 & 6.89 & 1.99 \\
Soil color index (SCI) & 3.12 & 4.39 & 5.44 & 2.30 & 2.56 \\
Iron oxide & 1.81 & 1.43 & 10.21 & 3.47 & 2.61 \\
Clay minerals & 1.44 & 3.80 & 2.92 & 4.99 & 3.25 \\
Available potassium & 0.64 & 4.34 & 2.51 & 3.78 & 6.80 \\
Available phosphorus & 2.89 & 7.05 & 4.93 & 4.59 & 0.68 \\
Water & 4.61 & 6.12 & 6.11 & 3.94 & 4.30 \\
Mining area & 1 & 10.77 & 7.39 & 8.25 & 7.10 \\
Factories and enterprises & 6.03 & 12.41 & 8.94 & 12.40 & 6.73 \\
Livestock farm & 1.50 & 5.84 & 5.75 & 10.69 & 5.88 \\
Road & 1.53 & 5.12 & 11.11 & 1.35 & 6.83 \\
\hline
\end{tabular}

(a)

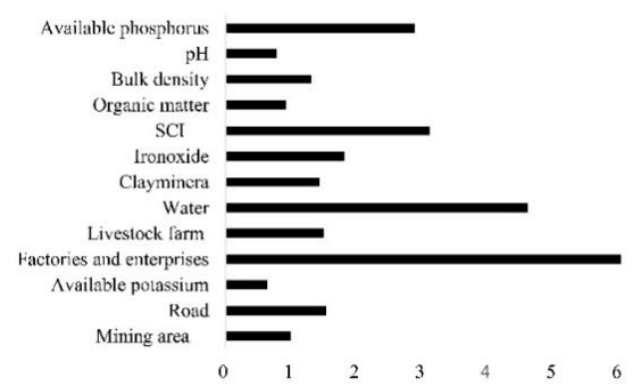

(c)

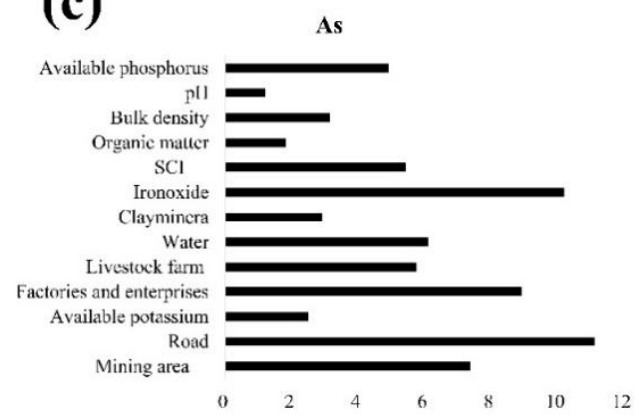

(b)

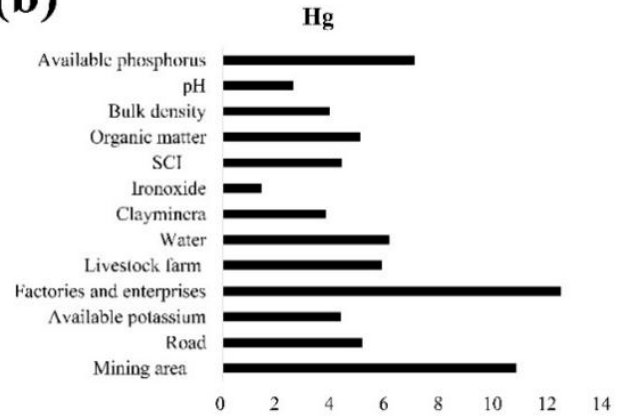

(d)

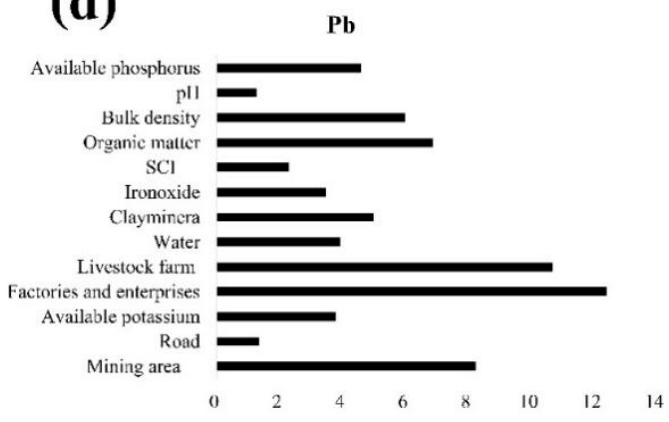

(e)

Cr

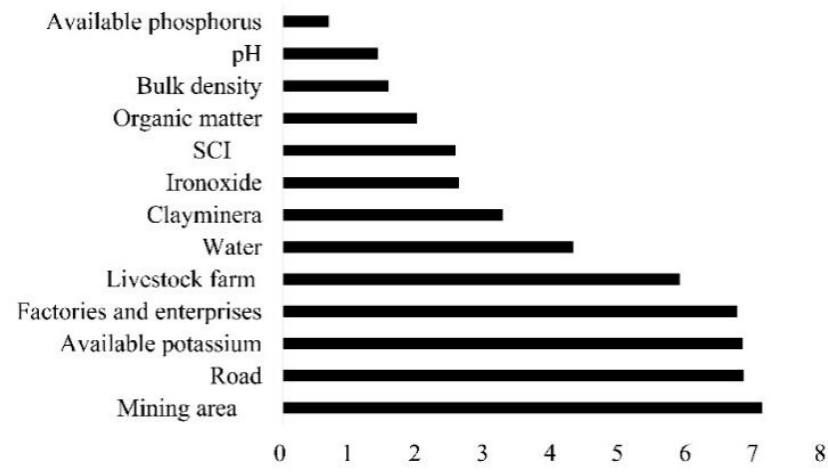

Figure 9. Plots of the variable importance measures in Xiangzhou. Variable importance measure results for (a) $\mathrm{Cd},(\mathbf{b}) \mathrm{Hg}$, (c) As, (d) $\mathrm{Pb}$, and (e) $\mathrm{Cr}$. 
Correlation analysis and principal component analysis both demonstrated that the origin consistency of $\mathrm{Hg}$ and $\mathrm{Pb}$ was high. In the random forest analysis, the top four artificial factors affecting their distribution were found to be factories, enterprises, mining areas, and livestock farms. Industrial and agricultural production lead to mercury contamination in the environmental soil [56]. In this study, $\mathrm{Hg}$ was more affected by human factors, whereas $\mathrm{Pb}$ was affected by the combined influence of human activities and natural accumulation.

The results of various analyses in this study illustrated that the origins of As and $\mathrm{Cr}$ were highly consistent. The random forest regression model showed that roads, factories, and water system distance from mining areas and farms were the common cumulative sources, indicating that the accumulation of these two potentially toxic elements was strongly affected by human activities. In the light of a previous research, industrial manufacturing and processing, mining industry, metal smelting and transportation in mining region, and livestock fertilizer from farm can lead to the enrichment of As and Cr [57]. Industrial activities and transportation also affect the levels of potentially toxic elements in regional dust fall, further affecting their contents in the surrounding soil [58]. As and $\mathrm{Cr}$ are exhausted into the environment with the exhaust gas of cars, while the wearing out of vehicle parts during transportation cause $\mathrm{As}$ and $\mathrm{Cr}$ to pollute the environmental soil along with dust and dirt in the atmosphere [59].

\section{Conclusions}

These properties of potentially toxic elements not only worsen the quality of the soil circumstance and change the ecological function of the soil but also directly or indirectly affect human health [60]. Carrying out environment risk assessment research can provide a basis for the scientific evaluation of potentially toxic element pollution of soil, pollution treatment, and reasonable soil redevelopment [61].

The three calculation methods used in this paper all showed that the soil was $\mathrm{Cr}$ pollution-free (low pollution); however, ecological risks of $\mathrm{As}$, and $\mathrm{Pb}$ still exist, with obvious differences [62]. $\mathrm{Cd}$ and $\mathrm{Hg}$ were the main risk factors, with imminent health and environment risks.

Long-term industrial pollution, mineral mining and processing, exhaust emissions from transportation, the application of manure from farms as fertilizer, and sewage irrigation are the main anthropogenic sources of toxic elements pollution in the cultivated soils [63]. In response to the pollution results from this investigation, in addition to continuing to control the production and processing of polluted gases and waste emissions in factories, it is also necessary to control the excessive introduction of potentially toxic elements from livestock manure into farmland soil environments to avoid further pollution, and potentially toxic elements in feces should be processed before being discharged into soil [64]. Inorganic passivating agents can be added to the feces, such as: fly ash, calcium bentonite, phosphate rock, or zeolite, which can effectively adsorb potentially toxic elements, thereby reducing their biological effectiveness [65].

Author Contributions: H.H. and Y.Z. conceived and designed the research; Y.-J.L. handled software; K.L., M.-Y.L., Y.T. and L.X. tested the heavy metals in soil; F.W. discussed the results. All authors have read and agreed to the published version of the manuscript.

Funding: This research was funded by the "Classification project of soil environmental quality of cultivated land in Xiangzhou".

Acknowledgments: Special thanks to the data provided from Xiangzhou government.

Conflicts of Interest: The authors declare no conflict of interest.

\section{References}

1. Md Anawar, H.; Chowdhury, R. Remediation of Polluted River Water by Biological, Chemical, Ecological and Engineering Processes. Sustainability 2020, 12, 7017. [CrossRef]

2. Yang, Y.; Christakos, G.; Guo, M.; Xiao, L.; Huang, W. Space-time quantitative source apportionment of soil heavy metal concentration increments. Environ. Pollut. 2017, 223, 560-566. [CrossRef] [PubMed] 
3. Ke, X.; Gui, S.; Huang, H.; Zhang, H.; Wang, C.; Guo, W. Ecological risk assessment and source identification for heavy metals in surface sediment from the Liaohe River protected area, China. Chemosphere 2017, 175, 473-481. [CrossRef] [PubMed]

4. Nanos, N.; Martín, J.A.R. Multiscale analysis of heavy metal contents in soils: Spatial variability in the Duero river basin (Spain). Geoderma 2012, 189, 554-562. [CrossRef]

5. Hou, D.; Li, F. Complexities surrounding China's soil action plan. Land Degrad. 2017, 28, 2315-2320. [CrossRef]

6. Chen, Z.; Shi, D. Spatial Structure Characteristics of Slope Farmland Quality in Plateau Mountain Area: A Case Study of Yunnan Province, China. Sustainability 2020, 12, 7230. [CrossRef]

7. Bandara, N.; Hettiarachchi, H.; Jensen, E.; Binoy, T.H. Upcycling Potential of Industrial Waste in Soil Stabilization: Use of Kiln Dust and Fly Ash to Improve Weak Pavement Subgrades Encountered in Michigan, USA. Sustainability 2020, 12, 7226. [CrossRef]

8. Kamta, F.N.; Schilling, J.; Scheffran, J. Insecurity, Resource Scarcity, and Migration to Camps of Internally Displaced Persons in Northeast Nigeria. Sustainability 2020, 12, 6830. [CrossRef]

9. Breiman, L. Random forests. Mach. Learn. 2001, 45, 5-32. [CrossRef]

10. Oves, M.; Khan, M.S.; Zaidi, A.; Ahmad, E. Soil contamination, nutritive value, and human health risk assessment of heavy metals: An overview. Toxic. Heavy Met. Legum. Bioremediat. 2012, 1, 1-28.

11. Brtnický, M.; Pecina, V.; Baltazár, T.; Vašinová Galiová, M.; Baláková, L.; Bęś, A.; Radziemska, M. Environmental Impact Assessment of potentially toxic elements in Soils Near the Runway at the International Airport in Central Europe. Sustainability 2020, 12, 7224. [CrossRef]

12. Xiao, L.; Zhou, Y.; Huang, H.; Liu, Y.-J.; Li, K.; Li, M.-Y.; Tian, Y.; Wu, F. Application of Geostatistical Analysis and Random Forest for Source Analysis and Human Health Risk Assessment of potentially toxic elements (PTEs) in Arable Land Soil. Int. Environ. Res. Public Health 2020, 17, 9296. [CrossRef] [PubMed]

13. Nehren, U.; Kirchner, A.; Heinrich, J. What do yellowish-brown soils and stone layers tell us about Late Quaternary landscape evolution and soil development in the humid tropics? A field study in the Serra dos Órgãos, Southeast Brazil. Catena 2016, 137, 173-190. [CrossRef]

14. Wrb I W G. World Reference Base for Soil Resources 2014 International Soil Classification System for Naming Soils and Creating Legends for Soil Maps[M]//World Reference Base for Soil Resources 2014. International Soil Classification System for Naming Soils and Creating Legends for Soil Maps. 2014. Available online: https:/ / ec.europa.eu/jrc/en/printpdf/151713 (accessed on 26 December 2020).

15. Hodson, M.E. The need for sustainable soil remediation. Elements 2010, 6, 363-368. [CrossRef]

16. Soriano, H.; Maria, C. Environmental Risk Assessment of Soil Contamination. Environ. Risk Assess. Soil Contam. 2014. [CrossRef]

17. Adamo, P.; Iavazzo, P.; Albanese, S.; Agrelli, D.; de Vivo, B.; Lima, A. Bioavailability and soil-to-plant transfer factors as indicators of potentially toxic element contamination in agricultural soils. Sci. Total Environ. 2014, 500-501, 11-22. [CrossRef]

18. Mazurek, R.; Kowalska, J.; Gąsiorek, M.; Zadrożny, P.; Józefowska, A.; Zaleski, T.; Kępka, W.; Tymczuk, M.; Orłowska, K. Assessment of heavy metals contamination in surface layers of Roztocze National Park forest soils (SE Poland) by indices of pollution. Chemosphere 2017, 168, 839-850. [CrossRef]

19. Vareda, J.P.; Valente, A.J.; Duraes, L. Heavy metals in Iberian soils: Removal by current adsorbents/amendments and prospective for aerogels. Adv. Colloid Interface Sci. 2016, 237, 28-42. [CrossRef]

20. Chandrasekaran, A.; Ravisankar, R.; Harikrishnan, N.; Satapathy, K.K.; Prasad, M.V.R.; Kanagasabapathy, K.V. Multivariate statistical analysis of heavy metal concentration in soils of Yelagiri Hills, Tamilnadu, India-Spectroscopical approach. Spectrochim. Acta Part A Mol. Biomol. Spectrosc. 2015, 137, 589-600. [CrossRef]

21. Huo, Z.; Tian, J.; Wu, Y.; Ma, F. A Soil Environmental Quality Assessment Model Based on Data Fusion and Its Application in Hebei Province. Sustainability 2020, 12, 6804. [CrossRef]

22. Liu, H.; Yang, R.; Zhou, Z.; Huang, D. Regional Green Eco-Efficiency in China: Considering Energy Saving, Pollution Treatment, and External Environmental Heterogeneity. Sustainability 2020, 12, 7059. [CrossRef]

23. Arditsoglou, A.; Samara, C. Levels of total suspended particulate matter and major trace elements in Kosovo: A source identification and apportionment study. Chemosphere 2005, 59, 669-678. [CrossRef] [PubMed]

24. Buatmenard, P.; Chesselet, R. Variable influence of the atmospheric flux on the trace metal chemistry of oceanic suspended matter. Earth Planet. Sci. Lett. 1979, 42, 399-411. [CrossRef]

25. Burges, A.; Epelde, L.; Garbisu, C. Impact of repeated single-metal and multimetal pollution events on soil quality. Chemosphere 2015, 120, 8-15. [CrossRef]

26. Bzdusek, P.A.; Lu, J.; Christensen, E.R. PCB Congeners and Dechlorination in Sediments of Sheboygan River, Wisconsin, Determined by Matrix Factorization. Environ. Sci. Technol. 2006, 40, 120-129. [CrossRef]

27. Jiao, X.; Teng, Y.; Zhan, Y. Soil Heavy Metal Pollution and Risk Assessment in Shenyang Industrial District, Northeast China. PLoS ONE 2015, 10, e0127736. [CrossRef]

28. Yaylaliabanuz, G. Heavy metal contamination of surface soil around Gebze industrial area, Turkey. Microchem. J. 2011, 99, 82-92. [CrossRef]

29. Arik, F.; Yaldiz, T. Heavy Metal Determination and Pollution of the Soil and Plants of Southeast Tavşanlı (Kütahya, Turkey). Clean-Soil Air Water 2010, 38, 1017-1030. [CrossRef]

30. Comero, S.; Vaccaro, S.; Locoro, G. Characterization of the Danube River sediments using the PMF multivariate approach. Chemosphere 2014, 95, 329-335. [CrossRef] 
31. Guney, M.; Zagury, G.J.; Dogan, N. Exposure assessment and risk characterization from trace elements following soil ingestion by children exposed to playgrounds, parks and picnic areas. Hazard. Mater. 2010, 182, 656-664. [CrossRef]

32. Jiménez-Ballesta, R.; García-Navarro, F.J.; Bravo, S.; Amoros, J.A.; Pérez de los Reyes, C.; Mejias, M. Environmental assessment of potential toxic elements contents in the inundated floodplain área of Tablas de Daimiel wetland (Spain). Environ. Geochem. Health 2017, 39, 1159-1177. [CrossRef] [PubMed]

33. Kara, M.; Dumanoglu, Y.; Altiok, H. Spatial distribution and source identification of trace elements in topsoil from heavily industrialized region, Aliaga, Turkey. Environ. Monit. Assess. 2014, 186, 6017-6038. [CrossRef] [PubMed]

34. Kim, M.; Deshpande, S.R.; Crist, K.C. Source apportionment of fine particulate matter (PM 2.5) at a rural Ohio River Valley site. Atmos. Environ. 2007, 41, 9231-9243. [CrossRef]

35. Roy, M.; Mcdonald, L.M. Metal Uptake in Plants and Health Risk Assessments in Metal-Contaminated Smelter Soils. Land Degrad. Dev. 2015, 26, 785-792. [CrossRef]

36. Salonen, V.; Korkkaniemi, K. Influence of parent sediments on the concentration of heavy metals in urban and suburban soils in Turku, Finland. Appl. Geochem. 2007, 22, 906-918. [CrossRef]

37. Schaefer, K.; Einax, J.W. Source Apportionment and Geostatistics: An Outstanding Combination for Describing Metals Distribution in Soil. Clean-Soil Air Water 2016, 44, 877-884. [CrossRef]

38. Vaccaro, S.; Sobiecka, E.; Contini, S.; Locoro, G.; Free, G.; Gawlik, B.M. The application of positive matrix factorization in the analysis, characterisation and detection of contaminated soils. Chemosphere 2007, 69, 1055-1063. [CrossRef]

39. Fei, J.-C.; Min, X.-B.; Wang, Z.-X.; Pang, Z.-H.; Liang, Y.-J.; Ke, Y. Health and ecological risk assessment of heavy metals pollution in an antimony mining region: A case study from South China. Environ. Sci. Pollut. Res. Int. 2017, 24, 27573-27586. [CrossRef]

40. Hu, B.; Xue, J.; Zhou, Y.; Shao, S.; Fu, Z.; Li, Y.; Chen, S.; Chen, L.; Shi, Z. Modelling bioaccumulation of heavy metals in soil-crop ecosystems and identifying its controlling factors using machine learning. Environ. Pollut. 2020, 262, 114308. [CrossRef]

41. Xu, R.; Sun, X.; Han, F.; Li, B.; Xiao, E.; Xiao, T.; Yang, Z.; Sun, W. Impacts of antimony and arsenic co-contamination on the river sedimentary microbial community in an antimony-contaminated river. Sci. Total Environ. 2020, 713, 136451. [CrossRef]

42. Zhou, X.Y.; Wang, X.R. Impact of industrial activities on heavy metal contamination in soils in three major urban agglomerations of China. J. Clean. Prod. 2019, 230, 1-10. [CrossRef]

43. El Azhari, A.; Rhoujjati, A.; El Hachimi, M.L.; Ambrosi, J.-P. Pollution and ecological risk assessment of heavy metals in the soil-plant system and the sediment-water column around a former $\mathrm{Pb} / \mathrm{Zn}$-mining area in NE Morocco. Ecotoxicol. Environ. Saf. 2017, 144, 464-474. [CrossRef] [PubMed]

44. Yi, Y.; Yang, Z.; Zhang, S. Ecological risk assessment of heavy metals in sediment and human health risk assessment of heavy metals in fishes in the middle and lower reaches of the Yangtze River basin. Environ. Pollut. 2011, 159, 2575-2585. [CrossRef] [PubMed]

45. He, X.; Song, X.; Pang, Y.; Li, Y.; Chen, B.; Feng, Z. Distribution, sources, and ecological risk assessment of SVOCs in surface sediments from Guan River Estuary, China. Environ. Monit. Assess. 2014, 186, 4001. [CrossRef] [PubMed]

46. Kadi, M.W. "Soil Pollution Hazardous to Environment": A case study on the chemical composition and correlation to automobile traffic of the roadside soil of Jeddah city, Saudi Arabia. J. Hazard. Mater. 2009, 168, 1280-1283. [CrossRef]

47. Mukherjee, A.B.; Zevenhoven, R.; Brodersen, J. Mercury in waste in the European Union: Sources, disposal methods and risks. Resour. Conserv. Recycl. 2004, 42, 155-182. [CrossRef]

48. Geng, F.; Cai, C.; Tie, X. Analysis of VOC emissions using PCA/APCS receptor model at city of Shanghai, China. J. Atmos. Chem. 2009, 62, 229-247. [CrossRef]

49. Josse, J.; Husson, F. Selecting the number of components in principal component analysis using cross-validation approximations. Comput. Stat. Data Anal. 2012, 56, 1869-1879. [CrossRef]

50. Moghtaderi, H.; Shakeri, T.; Andrés Rodríguez-Seijo, A. Potentially Toxic Element Content in Arid Agricultural Soils in South Iran. Agronomy 2020, 10, 564. [CrossRef]

51. Davis, H.T.; Aelion, C.M.; Mcdermott, S. Identifying natural and anthropogenic sources of metals in urban and rural soils using GIS-based data, PCA, and spatial interpolation. Environ. Pollut. 2009, 157, 2378-2385. [CrossRef]

52. Jimenez-Ballesta, R.; Bravo, S.; Amorós, J.A.; Pérez-De-Los-Reyes, C.; García-Giménez, R.; Higueras, P.; Garcia-Navarro, F. Mineralogical and Geochemical Nature of Calcareous Vineyard Soils from Alcubillas (La Mancha, Central Spain). Int. Environ. Res. Public Health 2020, 17, 6229. [CrossRef] [PubMed]

53. Jiang, Y.; Chao, S.; Liu, J.; Yang, Y.; Chen, Y.; Zhang, A.; Cao, H. Source apportionment and health risk assessment of heavy metals in soil for a township in Jiangsu Province, China. Chemosphere 2017, 168, 1658-1668. [CrossRef] [PubMed]

54. Fernandez, S.; Cotosyanez, T.R.; Rocapardinas, J. Geographically weighted principal components analysis to assess diffuse pollution sources of soil heavy metal: Application to rough mountain areas in Northwest Spain. Geoderma 2018, 311, 120-129. [CrossRef]

55. Johansson, C.; Norman, M.; Burman, L. Road traffic emission factors for heavy metals. Atmos. Environ. 2009, 43, 4681-4688. [CrossRef]

56. Oconnor, D.; Hou, D.; Ok, Y.S. Sustainable in situ remediation of recalcitrant organic pollutants in groundwater with controlled release materials: A review. J. Control. Release 2018, 283, 200-213. [CrossRef] [PubMed]

57. Peng, T.; Oconnor, D.; Zhao, B. Spatial distribution of lead contamination in soil and equipment dust at children's playgrounds in Beijing, China. Environ. Pollut. 2019, 245, 363-370. [CrossRef] 
58. Yu, X.; Li, H.; Doluschitz, R. Towards Sustainable Management of Mineral Fertilizers in China: An Integrative Analysis and Review. Sustainability 2020, 12, 7028. [CrossRef]

59. Xie, W.; Peng, C.; Wang, H.; Chen, W. Health Risk Assessment of Trace Metals in Various Environmental Media, Crops and Human Hair from a Mining Affected Area. Int. Environ. Res. Public Health 2017, 14, 1595. [CrossRef]

60. Young, F.J.; Hammer, R.D. Defining Geographic Soil Bodies by Landscape Position, Soil Taxonomy, and Cluster Analysis. Soil Sci. Soc. Am. J. 2000, 64, 989-998. [CrossRef]

61. Zhang, P.; Hou, D.; Oconnor, D. Green and Size-Specific Synthesis of Stable Fe-Cu Oxides as Earth-Abundant Adsorbents for Malachite Green Removal. ACS Sustain. Chem. Eng. 2018, 6, 9229-9236. [CrossRef]

62. Maanan, M.; Saddik, M.; Maanan, M.; Chaibi, M.; Assobhei, O.; Zourarah, B. Environmental and ecological risk assessment of heavy metals in sediments of Nador lagoon, Morocco. Ecol. Indic. 2015, 48, 616-626. [CrossRef]

63. Li, Q.; Gu, F.; Zhou, Y.; Xu, T.; Wang, L.; Zuo, Q.; Xiao, L.; Liu, J.; Tian, Y. Changes in the Impacts of Topographic Factors, Soil Texture, and Cropping Systems on Topsoil Chemical Properties in the Mountainous Areas of the Subtropical Monsoon Region from 2007 to 2017: A Case Study in Hefeng, China. Int. Environ. Res. Public Health 2021, 18, 832. [CrossRef]

64. Pekey, H.; Dogan, G. Application of positive matrix factorisation for the source apportionment of heavy metals in sediments: A comparison with aprevious factor analysis study. Microchem. J. 2013, 106, 233-237. [CrossRef]

65. Micó, C.; Recatalá, L.; Peris, M.; Sánchez, J. Assessing heavy metal sources in agricultural soils of an European Mediterranean area by multivariate analysis. Chemosphere 2006, 65, 863-872. [CrossRef] [PubMed] 